\title{
Do Medical Marijuana Laws Increase Hard-Drug Use?
}

\author{
Yu-Wei Luke Chu Victoria University of Wellington
}

\begin{abstract}
Medical marijuana laws generate significant debate regarding drug policy. For instance, if marijuana is a complement to hard drugs, then these laws would increase the usage not only of marijuana but also of hard drugs. In this paper I study empirically the effects of medical marijuana laws by analyzing data on drug arrests and treatment admissions. I find that medical marijuana laws increase these proxies for marijuana consumption by around 10-15 percent. However, there is no evidence that cocaine and heroin usage increases. From the arrest data, the estimates indicate a $0-15$ percent decrease in possession arrests for cocaine and heroin combined. From the treatment data, the estimates show a 20 percent decrease in admissions for heroin-related treatment, although there is no significant effect for cocaine-related treatment. These results suggest that marijuana may be a substitute for heroin, but it is not strongly correlated with cocaine.
\end{abstract}

I believe marijuana should be illegal in our country. It is the pathway to drug usage by our society, which is a great scourge-which is one of the great causes of crime in our cities. (Mitt Romney, October 4, 2007 [Altieri 2012])

I believe that marijuana is a gateway drug. (John McCain, August 11, 2007 [Zaitchik 2008])

\section{Introduction}

The idea that marijuana is a complement to hard drugs such as cocaine and heroin, or even a gateway to them, is an important but controversial justification for

This paper is a revision of a chapter in my dissertation submitted to Michigan State University in 2013. I am deeply grateful to Gary Solon, Todd Elder, and Jeff Biddle for their guidance. I thank the editor and an antonymous referee for helpful comments that have greatly improved this paper. Thanks also go to Johanna Catherine Maclean, D. Mark Anderson, Christopher Carpenter, Paul Calcott, Harold Cuffe, and seminar participants at the 2014 American Society of Health Economists biennial conference, Massey University, New Zealand Econometric Study Group meeting, and Victoria University of Wellington for discussions and suggestions. Special thanks to Christopher Smith for excellent editing service. All errors and omissions are my own.

[Journal of Law and Economics, vol. 58 (May 2015)]

(c) 2015 by The University of Chicago. All rights reserved. 0022-2186/2015/5802-0016\$10.00 
marijuana prohibition that has had a strong influence on US drug policy. The literature published in past decades on the relationship between marijuana and other substances is extensive, but a causal link has still not been established. Ethical and legal constraints prevent controlled experiments on illegal drugs using human subjects, but even the evidence from animal experiments is not conclusive (Solinas, Panlilio, and Goldberg 2004; Ellgren, Spano, and Hurd 2007). A key difficulty in identifying any causal effect of marijuana use on hard-drug use is finding a mechanism that generates arguably exogenous variation in marijuana consumption.

Medical marijuana legalization represents a major change in US policy toward marijuana in recent years. As of July 2014, 22 states and the District of Columbia had passed laws that allow individuals with designated conditions to use marijuana for medical purposes. Although the direct effects of these laws are limited to legally qualified patients, it is a popular belief that legalization of medical marijuana has increased illegal marijuana use among nonpatients as well (O'Connor 2011; Leger 2012). Medical legalization may diminish the stigma associated with the drug, and people may perceive lower health and legal risks of smoking marijuana (Khatapoush and Hallfors 2004). Some evidence also suggests that medical marijuana may commonly leak from legally qualified patients or dispensaries to illegal users (Thurstone, Lieberman, and Schmiege 2011; Salomonsen-Sautel et al. 2012). In fact, lobbying groups behind medical marijuana laws, such as the National Organization for the Reform of Marijuana Laws, consider such legislation to be the first step toward full legalization. Two states with medical marijuana legislation (hereafter, medical marijuana states), Colorado and Washington, successfully passed referenda to legalize marijuana for recreational use in November 2012.

The potential effects of medical marijuana legalization on marijuana and harddrug use not only are policy relevant but can also provide evidence on the relationship between marijuana and other substances. Some empirical evidence suggests that marijuana consumption increases after medical marijuana legalization. For example, Anderson, Hansen, and Rees (2014) find that the price of high-quality marijuana decreases over time after legalization. Chu (2014) shows that medical marijuana laws are associated with a $10-20$ percent increase in arrests for marijuana possession and related substance abuse treatment admissions. Wen, Hockenberry, and Cummings (2015), which uses the restricted version of the National Survey on Drug Use and Health (NSDUH) for the years 2004-11, finds large effects of these laws: an increase of about 15-25 percent in marijuana use, on both the intensive and extensive margins, as well as an increase in marijuana dependence. The notion that marijuana is a complement to hard drugs, either through contemporary complementarity or intertemporal complementarity, leads many people to be concerned that the use of hard drugs, such as cocaine and heroin, will consequently increase. In fact, this is one of the major reasons why federal agencies such as the Drug Enforcement Administration (DEA) and the Office of National Drug Control Policy firmly oppose medical marijuana laws 
and continue to list marijuana as a Schedule I drug (DEA 2014). Nevertheless, except for Wen, Hockenberry, and Cummings (2015), which does not find any significant effect of these laws on cocaine and heroin use, empirical evidence on the relationship between medical marijuana laws and hard-drug use is almost nonexistent.

To contribute to the literature on this question, in this paper I employ two data sets to examine whether medical marijuana laws-and the associated increase in marijuana use-affect cocaine and heroin usage. I study drug possession arrests from the Uniform Crime Reporting (UCR) Program for the years 19922011 (FBI 1992-2011). As the arrest data do not distinguish between cocaine and heroin, and since arrests could also be biased by changes in law enforcement, I supplement the UCR data by examining substance abuse treatment admissions from the Treatment Episode Data Set (TEDS) for the years 1992-2011 (SAMHSA 1992-2011). Although arrests and treatments do not measure drug use directly, and they reflect effects only on drug arrestees and treatment patients rather than the general population, these proxies have several advantages over survey data such as that from the NSDUH. First, these data are available for earlier years and cover more states with law changes. Second, they provide many more observations of hard-drug users. According to the NSDUH data, the past-year prevalence rates in the United States are around 1-2 percent for cocaine and .2 percent for heroin. These low prevalence rates suggest that the sample sizes at the state level in most representative data sets are probably not large enough to provide precision. For instance, while the NSDUH is the largest survey of its kind in the United States, its sample size in most states is only 900 people (600 adults). In fact, the public-use state-level data from the NSDUH are available only as 2-year moving averages, because of a concern over insufficient statistical power. In contrast, the UCR arrest data are available at the city level, and the TEDS data contain 1.5-2 million substance abuse treatment admissions each year, of which cocaine and heroin abuse account for 40 percent. Finally, these data are objective measures, and they do not suffer from the self-reporting bias that is common in survey data (Golub, Liberty, and Johnson 2005; Harrison and Hughes 1997). This is a particular concern in the current context because medical marijuana laws are expected to change the public perception of marijuana. Indeed, Miller and Kuhns (2012) find that people report marijuana usage more honestly after the passage of medical marijuana laws. If these laws also reduce the stigma on usage of other illicit drugs, there could be a spurious relationship between marijuana and cocaine or heroin due to people changing their reporting behaviors.

I adopt a difference-in-differences research design and estimate reduced-form models for the effects of these laws, controlling for city or state and year fixed effects and city- or state-specific time trends. I find evidence supporting the popular notion that marijuana use does increase after the passage of medical marijuana laws. The estimates indicate a 10-15 percent increase in arrests for marijuana possession and roughly a 10 percent increase in marijuana-related treatment admissions among adults. However, in contrast to what a contemporary or inter- 
temporal complementarity would predict, I do not find strong evidence that the usage of cocaine and heroin increases. In fact, almost all of the estimates have negative signs, which suggests that medical marijuana laws could have a negative effect on hard-drug use. The estimates of possession arrests for cocaine and heroin combined are uniformly negative, while the magnitudes fluctuate from close to 0 to a 15 percent decrease, depending on the model's specifications. In the treatment data, I find that medical marijuana laws are associated with a 15-20 percent decrease in heroin-related treatment admissions but that they have no significant effect on cocaine-related treatment admissions.

This research is important for several reasons. First, this paper employs a new policy tool-medical marijuana laws-for detecting the effects of marijuana on hard-drug use. Most previous studies either use instrumental variables that are largely based on cross-sectional variations, such as marijuana possession penalties and state excise taxes on beer, or try to model individual heterogeneity econometrically. All of these approaches have some limitations in the context of drug consumption. Second, the causal effects of medical marijuana laws on marijuana and hard-drug usage are at the core of the current policy debate. In particular, as treatment patients are heavy users who are associated with negative health and social outcomes, understanding the causal effects among this subpopulation is particularly relevant to the design of policy. Finally, the results indicate some direct costs incurred by medical marijuana laws, such as an increase in marijuana-related treatment admissions, while they also suggest that some unintended positive externalities may exist. Future cost-benefit analysis may utilize these findings to obtain more precise estimates for the effects of medical marijuana laws.

This paper proceeds as follows: Section 2 briefly describes medical marijuana laws, and Section 3 reviews the relevant literature. I discuss the data and results from the UCR regarding arrests in Section 4 and those from the TEDS regarding treatment admissions in Section 5. I offer my conclusions in Section 6.

\section{Medical Marijuana Laws}

States with effective medical marijuana laws are presented in Table $1 .{ }^{1}$ Medical marijuana laws permit patients with legally designated diseases and syndromes to use marijuana as a treatment. The designated conditions are often as follows: AIDS, anorexia, arthritis, cachexia, cancer, chronic pain, glaucoma, migraines, persistent muscle spasms, severe nausea, seizures, and sclerosis. Some laws, however, such as that in California, also allow use for "any other illness for which marijuana provides relief” (Cal. Health \& Safety Code 11362.5[b][1][A]). Patients can legally possess marijuana up to a fixed amount. In many states, they can cultivate marijuana on their own. These laws also allow caregivers (most of whom are patients as well) to grow and provide marijuana to patients on a not-for-profit

\footnotetext{
${ }^{1}$ See Table A1 in the online appendix for more details of these laws. Pacula, Boustead, and Hunt (2014) provide a detailed legal analysis of the diversity of medical marijuana laws.
} 
Table 1

State Medical Marijuana Laws as of July 2014

\begin{tabular}{|c|c|c|}
\hline State & Date Effective & Dispensary $^{\mathrm{a}}$ \\
\hline Alaska & March 4, 1999 & No \\
\hline Arizona & April 13, 2011 & Yes \\
\hline California & November 6, 1996 & Yes $^{b}$ \\
\hline Colorado & June 1, 2001 & Yes $^{b}$ \\
\hline Connecticut & May 31, 2012 & Yes \\
\hline Delaware & July 1, 2011 & Yes \\
\hline District of Columbia & July 27, 2010 & Yes \\
\hline Hawaii & December 28, 2000 & No \\
\hline Illinois & January 1, 2014 & Yes \\
\hline Maine & December 22, 1999 & Yes (2009) \\
\hline Maryland & June 1, 2014 & Yes \\
\hline Massachusetts & January 1, 2013 & Yes \\
\hline Michigan & December 4, 2008 & No \\
\hline Minnesota & May 30, 2014 & Yes \\
\hline Montana & November 2, 2004 & No \\
\hline Nevada & October 1, 2001 & No \\
\hline New Hampshire & July 23, 2013 & Yes \\
\hline New Jersey & January 18, 2010 & Yes \\
\hline New Mexico & July 1, 2007 & Yes \\
\hline New York & July 5, 2014 & Yes \\
\hline Oregon & December 3, 1998 & No \\
\hline Rhode Island & January 3, 2006 & Yes (2009) \\
\hline Vermont & July 1,2004 & Yes (2011) \\
\hline Washington & November 3, 1998 & No \\
\hline
\end{tabular}

Note. Only states that passed laws before 2012 are coded as medical marijuana states. See ProCon.org (2013) for legal documents and details of laws.

${ }^{2}$ Years indicate the effective dates of amendments that legalize dispensaries.

${ }^{\mathrm{b}}$ The medical marijuana law explicitly recognizes the existence of dispensaries but is silent as to their legality.

basis. In most states, it is mandatory to register and renew the registration every year to be a qualified medical marijuana patient or caregiver. ${ }^{2}$

In principle, these medical marijuana laws provide legal protection only for patients and caregivers. They do not change the legal status of the nonmedical use of marijuana. However, these loosely worded laws create a substantial gray area, and the legal boundary is blurred (Cohen 2010). This is probably done intentionally, as the lobbyists behind these laws consider such legislation a first step toward full legalization. A significant example of the legal gray area inherent in these laws is the legality of marijuana dispensaries. As most state medical marijuana laws did not directly authorize marijuana dispensaries prior to 2009, they existed only under the name of caregiver or patient cooperatives. Their prevalence depended largely on the attitude of the local government. For example, San Diego County has a very restrictive policy toward dispensaries, and its law enforcement orga-

\footnotetext{
${ }^{2}$ California created a registration program in 2004, but registration is voluntary. Maine passed an amendment in November 2009 that created a registration program, but it remains voluntary. Washington does not have a registration program.
} 
nizations actively cooperate with the DEA; the only county-licensed dispensary was forced to close in 2012 (Anderson 2012). In contrast, some sources claim that there are more marijuana dispensaries than Starbucks coffee shops or CVS pharmacies in Los Angeles and San Francisco (National Public Radio 2009; Coté et al. 2008). Yet local attitudes and law enforcement can change dramatically. For instance, in June 2010, Los Angeles ordered the closure of more than 70 percent of the 638 dispensaries then operating in the city.

Some ambiguities also exist for low-level marijuana possession offenses. For example, California requires only that a patient possess a "written or oral recommendation" from a physician, thus not requiring the recommendation to be documented (Cal. Health \& Safety Code 11362.5[d]). In general, there has been a softening in public attitudes toward marijuana in medical marijuana states, and federal agencies complain that cooperative relationships between federal and local law enforcement are deteriorating (GAO 2002). For instance, cities like Denver, San Francisco, Seattle, and Oakland passed initiatives either to legalize marijuana or to make marijuana possession offenses the lowest enforcement priority (Eddy 2010). In contrast, except for California, the number of legally qualified patients and marijuana dispensaries remained relatively small prior to 2009, and the direct effects on enforcement of low-level possession offenses appear to have been small because of the small number of legally qualified patients. ${ }^{3}$ To alleviate the tension between the federal and state governments, in 2009 the Obama administration stated that federal agencies would no longer seek to arrest medical marijuana users and suppliers so long as they conform to state laws. Since then, the number of registered patients and dispensaries has increased significantly (Caplan 2012; Mikos 2011; Sekhon 2009). Although this statement appeared largely to resolve the legal dispute between state and federal governments, the Obama administration's medical marijuana policy reversed somewhat in 2011, and there have been several cases of DEA raids on medical marijuana dispensaries that conform to state laws (Dickinson 2012).

\section{Literature Review}

\subsection{Medical Marijuana Laws and Drug Use}

There is little doubt that medical marijuana legalization increases marijuana consumption among legally qualified patients, because they are able to increase their consumption safely and easily. On the other hand, as most states require patients to register, and the number of registrants was small prior to 2009, one of the major policy debates is whether these laws also increase marijuana use among nonpatients. There is indeed a strong correlation among medical marijuana legislation, the perceived risk of marijuana, and marijuana use in survey data (Wall et al. 2011; Cerdá et al. 2012). However, the evidence supporting a causal rela-

\footnotetext{
${ }^{3}$ Although no official numbers are available for patients in states without registration, on the basis of the large number of dispensaries, it is believed that California has many more patients than other medical marijuana states.
} 
tionship is somewhat mixed. For example, Harper, Strumpf, and Kaufman (2012) show that the positive correlation between these laws and marijuana use from Wall et al. (2011) is quite sensitive to the inclusion of state fixed effects in the public-use NSDUH data. Anderson, Hansen, and Rees (2013) find that the price of high-quality marijuana decreases over time after medical marijuana legalization, but in another study they do not find a significant effect on marijuana use among teenagers (Anderson, Hansen, and Rees, forthcoming). In fact, almost all of the existing studies focus on juveniles and do not find any change in juvenile marijuana usage (O'Keefe and Earleywine 2011; Anderson, Hansen, and Rees, forthcoming; Lynne-Landsman, Livingston, and Wagenaar 2013; Choo et al. 2014). Although the marijuana prevalence rate is higher among young adults than among juveniles, very few studies focus on adults. Gorman and Huber (2007) use a time-series framework and do not find any significant change in marijuana use among arrestees, but their sample is limited to a small proportion of arrestees with available urine test results from four cities in a short time span.

One reason why many studies do not find an increase in marijuana usage could be that they do not consider the intensive margin. A similar example is that zero-tolerance laws only decrease heavy drinking while having no effect on participation in drinking (Carpenter 2007). Moreover, data quality seems to be an important issue in many of the existing studies. For example, Harper, Strumpf, and Kaufman (2012) apply the standard fixed-effects model to the public-use NSDUH data for 2002-3 to 2008-9. However, state-level marijuana use rates from the public-use NSDUH are reported only as 2-year moving averages (predicted values from a logistic model). The fixed-effects estimators may not be very reliable because the data are intended to reduce within-state variations, and only five states had changes in law during their sample period. Both Wall et al. (2012) and Chu (2014) point out that the results from Harper, Strumpf, and Kaufman (2012) are quite sensitive. Another related problem, as Anderson, Hansen, and Rees (forthcoming) note in their analysis of the National Longitudinal Survey of Youth 1997, is that the sample sizes are often quite small in many representative data sets for small states. In fact, obtaining a larger sample size and therefore increasing precision is the main reason the public-use NSDUH reports state-level use rates only as 2-year moving averages (Wright 2004).

Studies with higher-quality data do find strong effects of medical marijuana laws on marijuana use. Using the restricted version of the 2004-11 NSDUH, with access to individual-level data, Wen, Hockenberry, and Cummings (2015) suggest strong effects of medical marijuana legalization on both the extensive and intensive margins. For adults ages 21 and above, they find an increase in the probability of marijuana use of 15 percent and an increase in the probability of miarjuana dependence of 10 percent. In particular, they find an even larger increase for heavy marijuana use, with a 15-27 percent increase in the probability of marijuana dependence. This is consistent with the results from Chu (2014), which indicate an increase of about 10-20 percent in marijuana arrests and marijuana-related treatment admissions, which are arguably concentrated on 
heavy users. Moreover, in contrast to the literature that does not find any positive effect on teenagers, Wen, Hockenberry, and Cummings (2015) find an increase in marijuana use initiation of 5 percent for those 12-20 years old.

As mentioned previously, almost no empirical evidence has been published on the relationship between medical marijuana laws and hard-drug use. Drawing on the 1993-2009 Youth Risk Behavior Surveys, Anderson, Hansen, and Rees (2012) find that these laws have a negative effect, a decrease of around 15 percent in cocaine use among teenagers, but they suggest that the magnitude is implausibly large. The estimates of Wen, Hockenberry, and Cummings (2014) from the NSDUH for cocaine and heroin use have large estimated standard errors and are never significant. In the online appendix, I also report estimates of marijuana and cocaine use based on the public-use NSDUH data, and the results are consistent with those of Wen, Hockenberry, and Cummings (2015). ${ }^{4}$

\subsection{Relationship between Marijuana and Hard Drugs}

An extensive literature on the relationship between marijuana use and harddrug use has yielded many hypotheses but little consensus. I do not attempt to provide a comprehensive survey of that literature here. Rather, I focus on more recent studies that adopt different methodologies.

The seminal work in economics on drug abuse is the rational addiction model in Becker and Murphy (1988) that provides a theoretical framework for contemporal and intertemporal relationships between addictive substances. A straightforward empirical task for economists is to determine these relationships, for example, whether marijuana is a substitute for, or a complement to, hard drugs. Grossman and Chaloupka (1998) and Saffer and Chaloupka (1999) estimate demand functions for marijuana and cocaine and find that the price of cocaine is negatively correlated with marijuana use, while the status of marijuana depenalization is positively associated with cocaine use, which suggests that these are complements. On the other hand, recent studies based on laboratory control experiments reveal a more complex pattern, even though external validity may be a concern because of small sample sizes. The relationships between drugs seem to depend on the types of drugs used. For example, Petry and Bickel (1998) find that marijuana is a substitute for heroin for opioid-dependent patients, while Petry

\footnotetext{
${ }^{4}$ The public-use National Survey on Drug Use and Health (NSDUH) state-level data are reported as 2-year moving averages and are available from 2002 to 2012. I estimate linear models with state and year fixed effects using ordinary least squares regression. The estimates suggest that, for people ages 12 and above, medical marijuana laws result in a .76-percentage-point increase in past-month marijuana use, which is equivalent to an increase of around 10.8 percent. Moreover, the estimates imply an increase in the annual rate of first-time use of marijuana of around .47 of a percentage point (6.7 percent) for juveniles ages $12-17$ and of .84 of a percentage point (10.7 percent) for adults ages 18-25. On the other hand, I do not find any significant effect of medical marijuana laws on past-year cocaine use. The estimates become noisy and insignificant when state-specific linear time trends are included in the models, however, most likely because these measures of drug use are reported as 2-year moving averages in the public-use NSDUH data. Notice that Wen, Hockenberry, and Cummings (2014) include state-specific time trends in their models, and their results are very close to my estimates from specifications with only fixed effects and without time trends.
} 
(2001) finds that marijuana consumption is independent from cocaine use for alcoholics. Jofre-Bonet and Petry (2008) find that marijuana is a complement to heroin for heroin addicts but a substitute for heroin for cocaine addicts.

Another focus of the literature is the intertemporal complementarity between marijuana and hard drugs. In particular, a highly debated empirical question across many disciplines is the gateway hypothesis. Popularized by Kandel (1975), the gateway hypothesis is based on one of the most robust empirical observations: most hard-drug users started with less dangerous drugs, and there seems to be a staircase on which users of marijuana (or legal substances like alcohol) step up to cocaine and heroin. A gateway effect might be indeed causal, through physiological or psychological demand for stronger drug-induced pleasures and experiences, the consumption capital (of addictive drugs) of Becker and Murphy (1988). In addition, a gateway effect could come from social interactions like gaining access to hard drugs through participation in the illegal-drug market (MacCoun 1998). ${ }^{5}$

The infeasibility of performing controlled experiments makes it difficult to establish causality empirically because of unobserved heterogeneity. DeSimone (1998) uses marijuana possession penalties, beer taxes, and the presence of alcoholic parents as instrumental variables and finds strong evidence for marijuana being a gateway drug for cocaine. Fergusson, Boden, and Horwood (2006a) find strong evidence using longitudinal data and controlling for individual fixed effects (see also Kandel, Yamaguchi, and Klein 2006; MacCoun 2006; Fergusson, Boden, and Horwood 2006b). Because of the difficulty of finding a valid instrument, some researchers try to model unobserved heterogeneity econometrically. These studies generally find that unobserved heterogeneity is an important factor, but whether marijuana is a gateway drug remains unclear. For example, Pudney (2003) does not find a gateway effect after accounting for unobserved heterogeneity, while some other studies find marijuana to be a gateway drug to cocaine (van Ours 2003; Bretteville-Jensen, Melberg, and Jones 2008; Melberg, Jones, and Bretteville-Jensen 2010; Deza 2015). A line of research from epidemiology utilizes data on twins and finds a positive relationship between early marijuana use and the use of other illicit drugs (Lynskey et al. 2003; Agrawal et al. 2004; Lynskey, Vink, and Boomsma 2006). However, as Bound and Solon (1999) observe in their critique, one potential problem in these twin studies is that the reasons why observably identical twins may make different choices are unlikely to be exogenous. Since even evidence from animal experiments is not conclusive (Solinas, Panlilio, and Goldberg 2004; Ellgren, Spano, and Hurd 2007), the original proposer of the gateway hypothesis, Denise Kandel, concludes that the existing evidence for the gateway effect is at best mixed, because of the lack of a clear neurological mechanism (Kandel 2003).

\footnotetext{
${ }^{5}$ Note that if a gateway effect works through social interactions, then legalizing soft drugs and separating their markets from hard drugs would be a better policy. This is the rationale behind the policy in the Netherlands that allows the legal sale of marijuana in "coffee shops."
} 


\section{Results from the Uniform Crime Reporting Program Arrest Data}

\subsection{Uniform Crime Reporting Program Data}

The data on drug possession arrests used in this paper are from the UCR Program (FBI 1992-2011). Although variation in drug arrests is affected by changes in law enforcement, arrest data remain the single most widely available indicators of illegal-drug use within and across jurisdictions in the United States. The UCR arrest data provide monthly information on arrest counts by age, gender, and race in each crime category along with agency populations (estimated from the census) for state and local police agencies. Note that each arrest count does not necessarily represent a single individual, since a person may be arrested multiple times. Thus, the measure reflects changes in both the intensive and extensive margins. There are four UCR categories of drug possession arrests: marijuana; powder cocaine, crack cocaine, heroin, and other opium derivatives; "truly addicting synthetic narcotics;" and "other dangerous non-narcotic drugs" (most drugs in this category are methamphetamines). As the crack epidemic ended around the early to mid-1990s (DEA 1991; Fryer et al. 2013), and to be consistent with the starting point in the TEDS data, I use data on possession arrests from 1992-2011 (the most recent data available).

I use yearly aggregated arrest data hosted by the Inter-university Consortium for Political and Social Research; the FBI also reviews and checks the data using annual arrest totals (Akiyama and Propheter 2005). Since participation in the UCR Program is generally voluntary, many agencies do not report in every month or every year; even when an agency reports, it may not report data in all categories. One problem is that it is not possible to distinguish a true 0 from missing data. However, most missing data are from agencies with small populations and those that do not report for a whole year (Lynch and Jarvis 2008).

I focus on police agencies in cities with more than 50,000 residents because the FBI regularly checks and communicates with these agencies to ensure data quality (Akiyama and Propheter 2005). Since population tends to increase over time, I include earlier observations from the cities to make the panel more balanced if their populations are at least 25,000. Similarly to Carpenter (2007), and as is common in the criminology literature, I focus on adult male arrests, and I use cityyears only if a city reports arrests for marijuana or cocaine possession for at least 6 months during that year. ${ }^{6}$ (I include city-year observations from cities that report only in December, since some agencies appear to report only annually.) The sample covers 15 states that passed medical marijuana laws before 2012: Alaska, Arizona, California, Colorado, Delaware, Hawaii, Maine, Michigan, Montana, Nevada, New Jersey, New Mexico, Oregon, Rhode Island, and Washington. The

\footnotetext{
${ }^{6}$ I consider only males to be consistent with the existing literature and because males are more likely than females to be in the criminal justice system. For example, the possession arrest rates for adult males in my sample are four to seven times those for adult females. I focus on adults since rates of cocaine and heroin use among juveniles are fairly low. In addition, the juvenile justice system is very different from the adult system in areas such as procedures, incentives, and sanctions (Levitt 1998; Carpenter 2007; Terry-McElrath et al. 2014).
} 
District of Columbia and Vermont are not in the sample because of sample construction: the District of Columbia has missing population data for years after 1995 , and no city in Vermont in the UCR data has a population greater than 50,000 .

Do marijuana and cocaine possession arrests represent underlying drug use? Studies from criminology indicate that drug arrests generally are valid measures for illicit-drug use, especially of cocaine and heroin (Rosenfeld and Decker 1999; Warner and Coomer 2003; Moffatt, Wan, and Weatherburn 2012). Figures 1 and 2 provide evidence at the national level that also suggests that they are valid measures. The figures plot the yearly averages of the ratio of marijuana and cocaine possession arrests to all offense arrests along with marijuana and cocaine prices per pure gram. The marijuana prices are from the 2012 National Drug Control Strategy Data Supplement (Office of National Drug Control Policy 2012), and the cocaine prices are purchasing prices from the DEA's System to Retrieve Information from Drug Evidence. ${ }^{7}$ In Figures 1 and 2, the prices move in the opposite direction from arrests, which is consistent with a supply curve moving along a downward-sloping demand curve.

Following Carpenter (2007) and Fryer et al. (2013), I calculate the ratios of marijuana and cocaine possession arrests to all arrests of adult males. Although the arrest rate is straightforward and commonly used, arrest ratios can partially account for unobserved changes in local law enforcement and measurement errors in arrest rates from estimated populations. In addition, as the resources of law enforcement are typically limited, arrest ratios can capture fluctuations in total arrests due to changes in resources allocated. Table $\mathrm{C} 1$ in the online appendix presents the means and standard deviations of the arrest ratios of marijuana and cocaine and heroin possession for adult males ages 18 and above. Since the allocation of resources toward marijuana law enforcement is probably lower in states with medical marijuana laws, in Section 4.2, I propose an empirical model that can account for heterogeneity at the city level. ${ }^{8}$

\subsection{Results}

My primary empirical strategy involves estimating city- and year-specific arrests for drug possession as a function of whether the state had an effective medical marijuana law in place in that year. I begin by estimating the following model:

\footnotetext{
${ }^{7}$ I acquired System to Retrieve Information from Drug Evidence (STRIDE) data through a Freedom of Information Act request. I calculated average cocaine prices by obtaining the median price in each state and averaging the median prices to the national level. Average cocaine prices that exclude some extreme values are similar to median prices. See Horowitz (2001) and Arkes et al. (2008) for discussions of the STRIDE data.

${ }^{8}$ Table $\mathrm{C} 1$ shows that marijuana arrest ratios are lower in medical marijuana states. However, marijuana prevalence rates are higher in those states (Table B1 in the online appendix). The higher prevalence rates cannot be driven by medical marijuana patients, as that number was quite small prior to 2009.
} 


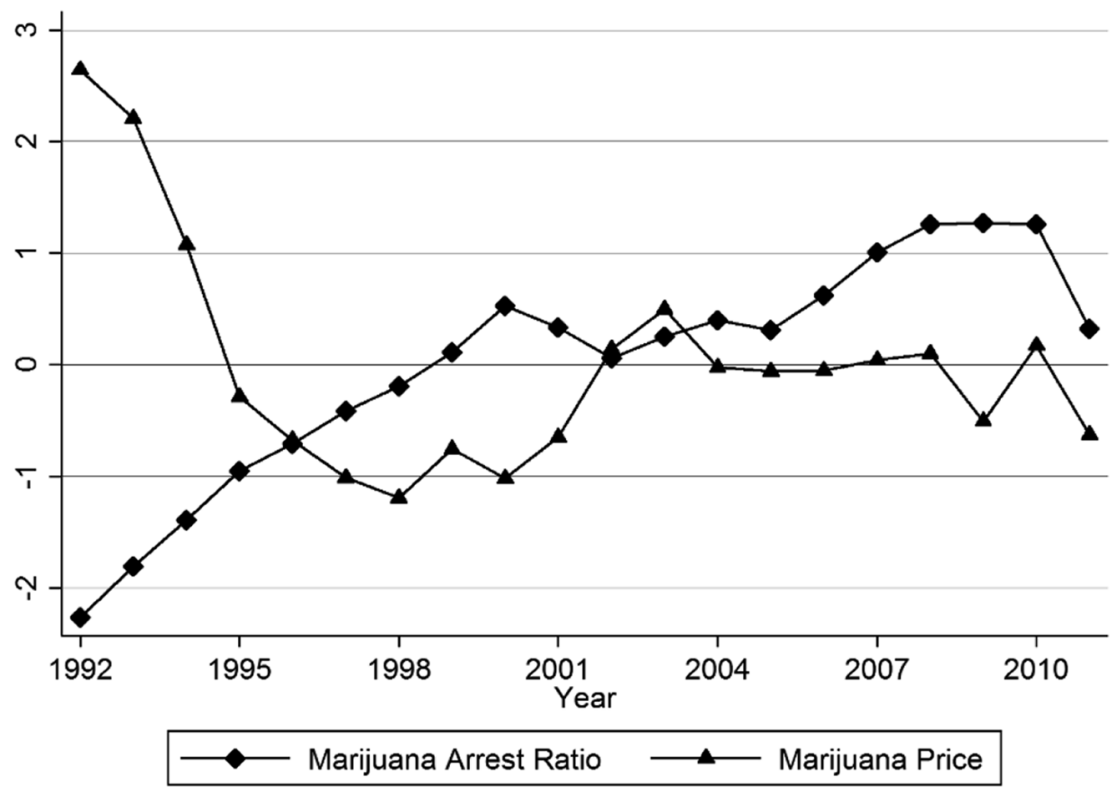

Figure 1. Marijuana arrests and prices, 1992-2011 (normalized)

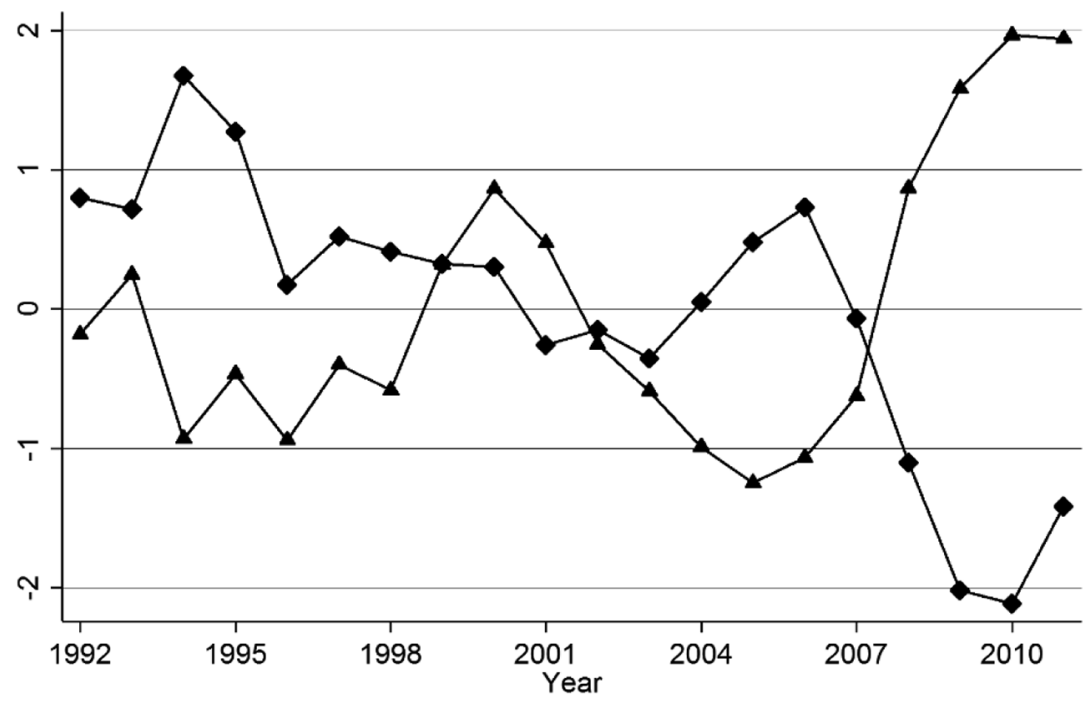

Cocaine and Heroin Arrest Ratio $\longrightarrow$ Cocaine Price

Figure 2. Cocaine and heroin arrests and prices, 1992-2011 (normalized) 


$$
\begin{aligned}
Y_{i s t}= & f\left(\beta \mathrm{Law}_{s t}+\text { Year Fixed Effects }_{t}+\text { City Fixed Effects }_{i}\right. \\
& \left.+ \text { City Time Trends }_{i t}+\text { Control Variables }_{i s t}+\varepsilon_{i s t}\right),
\end{aligned}
$$

where the dependent variable $Y_{\text {ist }}$ is marijuana or cocaine and heroin arrest ratios among adult males for city $i$ in state $s$ and year $t$. The dummy variable Law $_{s t}$ indicates whether state $s$ had a medical marijuana law during year $t$ and takes on fractional values for the years in which the law changed. ${ }^{9}$ The main control variable is a dummy variable for marijuana decriminalization in California (effective January 1, 2011) and Massachusetts (effective January 2, 2009). ${ }^{10}$ Other control variables include the ratio of city police officers to city residents (from the UCR data), state unemployment rates, log average income per capita, and log local and state expenditures per capita on health care, hospitals, and police protection. The sample sizes are smaller when these control variables are included because data on government expenditures were not collected by the Census Bureau for 2001 and 2003 because of sample redesign. In addition to city and year fixed effects, I include city-specific linear or quadratic time trends to capture time-varying unobservables such as law enforcement. These city-specific time trends are particularly important in the current context because addictiveness suggests a strong correlation in consumption, and thus drug use is likely to be trending. For instance, perhaps because of a more open attitude toward drug use, medical marijuana states tend to have higher rates of drug use even prior to medical marijuana legalization. Because a proportion of these drug users will become addicted and continue to use, there will be a spurious effect of medical marijuana laws on drug consumption if existing trends are not controlled for. As many of these arrest ratios have values very close to 0 , especially for cocaine and heroin arrests, I estimate equation (1) as a fixed-effect Poisson model; that is, $f(\cdot)$ is an exponential function. I also check the robustness of functional form by estimating a log-linear model. Throughout this paper, the estimated standard errors are clustered at the state level and therefore are robust to serial correlation, within-state spatial correlation, and heteroskedasticity.

Before discussing the empirical results, it should be noted that drug arrests are concentrated among heavy users and that they conceptually capture changes in both the extensive and intensive margins. Arrests in a particular city-year can be modeled as follows:

$$
A=\sum_{j=1}^{N} F_{j} \times P\left(X_{j}\right),
$$

where $N$ is the number of drug users; $F_{j}$ is individual $j$ 's transaction or use frequency; and $P\left(X_{j}\right)$ is the probability of being arrested per transaction or per use,

\footnotetext{
${ }^{9}$ There is normally a time lag between passing a referendum and its becoming an effective law (see Table A1 in the online appendix). In some cases the referendum was delayed (for example, Nevada) or even vetoed (for example, Arizona in 1996 and the District of Columbia in 1998) by the state government or Congress. Throughout this paper, as in Anderson, Hansen, and Rees (2013), the coding of $\mathrm{Law}_{s t}$ is based on the date the law became effective.

${ }^{10}$ The estimates for decriminalization are about -1.5 to -2 for marijuana arrests and .15 for cocaine and heroin arrests.
} 
a function of $X_{j}$, including city-specific factors such as local law enforcement and individual characteristics such as age and race. Conditional on arrest probability, equation (2) shows that drug arrests are concentrated among heavy users who have higher use or transaction frequencies. ${ }^{11}$ For simplicity, assume a homogenous probability of being arrested across $j$ and ignore potential heterogeneity in a city. ${ }^{12}$ Letting $\bar{F}$ be the average of $F_{j}$ and taking log values, then in a particular city-year

$$
\log A=\log N+\log \bar{F}+\log P .
$$

Differentiate both sides of equation (3), and the percentage change in arrests can be decomposed into the percentage change in drug use, either from the extensive or intensive margin, and the percentage change in arrest probability, which is a source of potential bias.

Table 2 presents the estimates for the effect of medical marijuana laws on marijuana arrests and cocaine and heroin arrests among adult males. The estimates of marijuana arrests in columns 1-3 are positive and significant regardless of timetrend specifications. On average, medical marijuana laws result in an 8.0-10.6 percent increase in the ratio of marijuana arrests to all arrests among adult males. The estimate is nearly identical with the inclusion of the full set of control variables (column 4). The effects of medical marijuana laws on marijuana arrests are seen to be even greater using a log-linear model, indicating a 16.2-17.0 percent increase in marijuana arrests, but the larger estimates could be because a log function is more sensitive to small values. Since city-specific time trends and fixed effects already account for any smooth-trending variables, and data are missing in some of these control variables, in the rest of this section I focus on the specification that includes marijuana decriminalization as the only control variable.

Note that each observation is a city-year, while Law $_{s t}$ varies only at the state level. So the estimates are disproportionately identified by states that have large populations and therefore more cities. ${ }^{13}$ To ensure that the results are not driven

\footnotetext{
${ }^{11}$ Because cocaine and heroin are highly addictive, the distinction between heavy users and light users may not be empirically relevant. On the other hand, because of the popularity of marijuana, such a distinction is important, as many marijuana users are only casual users. In fact, marijuana arrests are highly correlated with marijuana-related treatment, with correlation coefficients around .3-.5, so many marijuana arrestees are possibly heavy users, being treatment patients. The greater heterogeneity among marijuana users than among cocaine or heroin users may be one of the reasons why studies such as Rosenfeld and Decker (1999) find that cocaine arrests are more consistent with drug use in survey data than marijuana arrests.

${ }^{12}$ It is straightforward to generalize the decomposition to incorporate heterogeneity in arrest probability, for example, that younger populations and minorities are more likely to be arrested. In an econometric sense, the estimates remain consistent or unbiased as long as the arrest probability in each group does not change after legalization, but they reflect a weighted average of the legalization effects on each group, where the weight is positively correlated with each group's arrest probability.

${ }^{13}$ In a linear model, if the explanatory variables vary only at the group level, then the least squares estimates are numerically the same as the weighted least squares estimates from a group-level regression using group averages, where the weights are given by the numbers of observations in each group. In Table 2, because the model's specifications are not linear and there are some city-level variables such as city-specific trends, the weighted estimates from a state-level regression will not be numerically identical to the estimates from city-level regressions. But the intuition should apply.
} 


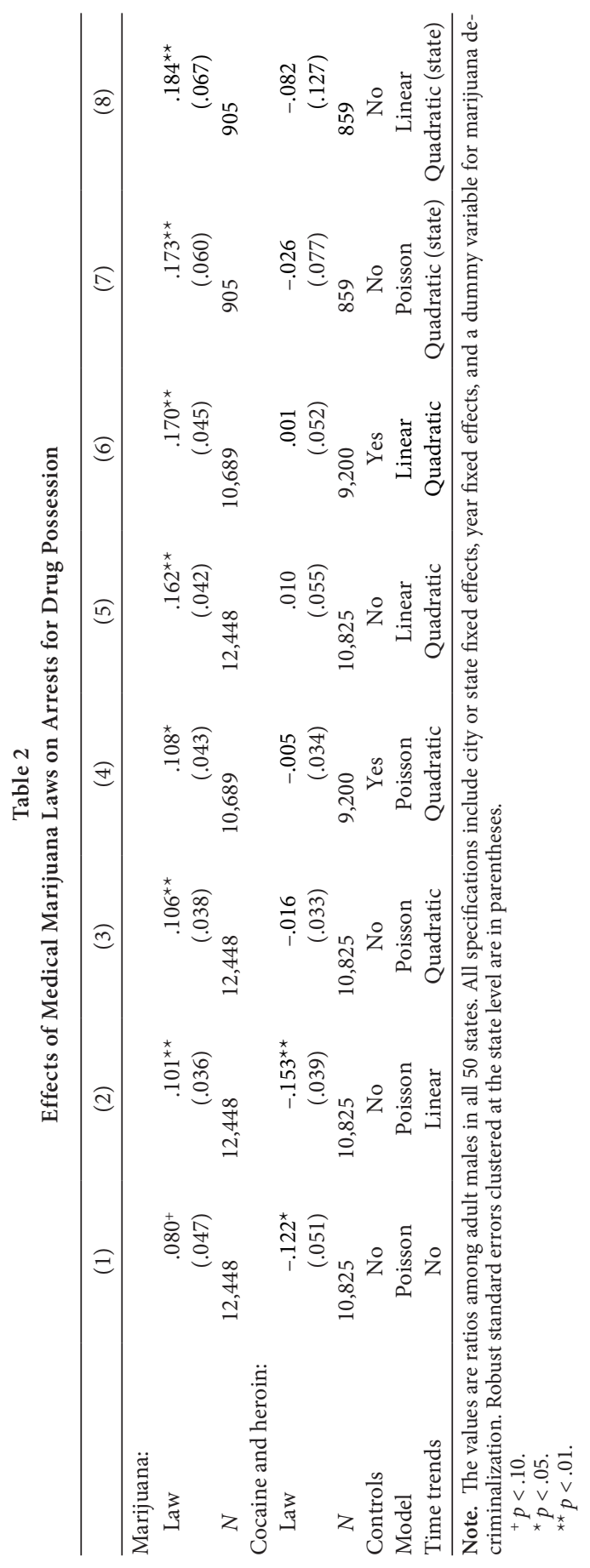


solely by larger states like California, I average marijuana or cocaine and heroin arrest ratios to the state level, so each state receives equal weight regardless of the number of city-years. The estimates from state-level averages are qualitatively similar to those in columns 1-6 regardless of the assumptions on functional form, and they suggest a 17.3-18.4 percent increase in marijuana arrests.

The estimates for cocaine and heroin in columns 1 and 2 suggest a decrease of 12.2-15.3 percent in arrest ratios. When I include city-specific quadratic time trends in the model, in columns 3-6, the estimates of cocaine and heroin arrests are essentially 0 , and the results are not sensitive to the inclusion of control variables or functional form assumptions. The estimates from state-level regressions also have negative signs but are insignificant. Clearly, there is no evidence that cocaine and heroin arrests increased after the passage of medical marijuana laws. In summary, my results suggest a positive effect on marijuana arrests of around 10-15 percent but no significant effect on cocaine and heroin arrests. These results are also consistent with the findings based on the NSDUH data from Wen, Hockenberry, and Cummings (2014). (See also the online appendix for estimates based on the public-use NSDUH data.)

One natural concern about the results from arrest data in Table 2 is that the estimates could be driven by changes in law enforcement. To address this concern, although indirectly, I examine the effects of medical marijuana laws separately for blacks and whites. If there is a considerable racial difference in the estimated effects, this would be a smoking gun indicating that the negative estimates for cocaine and heroin arrests are due to changes in law enforcement. It is well documented that African Americans are much more likely to be arrested for drug possession. Even though hard-drug-use rates, especially for crack cocaine, tend to be higher among African Americans, a nontrivial proportion of the racial difference in arrest risk can be attributed to law enforcement (Dannerbeck et al. 2006; Beckett, Nyrop, and Pfingst 2006; Donohue and Levitt 2001; Gross and Barnes 2002; Hernández-Murillo and Knowles 2004; Parker and Maggard 2005). There are several potential causes for this. In addition to possible racial profiling, African Americans often engage in risky purchasing behaviors such as making transactions in open places, or they tend to live in disadvantaged neighborhoods that attract more police attention and so they have an increased likelihood of arrest (Ramchand, Pacula, and Iguchi 2006; Beckett et al. 2005; Fellner 2009). ${ }^{14}$ Therefore, drug arrests among African Americans are expected to be more sensitive to changes in police behaviors. A controversial instance that attracts much attention is New York City's stop-and-frisk practice that has resulted in a huge increase in low-level drug possession arrests among minorities (Fellner 2009).

\footnotetext{
${ }^{14}$ For example, former New York Police Commissioner Lee Brown explained and defended the disproportionate racial impacts as follows: "In most large cities, the police focus their attention on where they see conspicuous drug use-street-corner drug sales-and where they get the most complaints. Conspicuous drug use is generally in your low-income neighborhoods that generally turn out to be your minority neighborhoods. . . . It's easier for police to make an arrest when you have people selling drugs on the street corner than those who are in the suburbs or in office buildings. The end result is that more blacks are arrested than whites because of the relative ease in making those arrests" (quoted in Fellner 2009, p. 41).
} 
To account for the fact that non-drug-offense rates and arrest risks are also higher among African Americans, I calculate arrest ratios for cocaine and heroin separately for adult blacks and whites. ${ }^{15}$ (The UCR data do not separate races by gender.) Table 3 presents the estimated effects of medical marijuana laws on drug arrest ratios for blacks and whites. Since African Americans are more affected by the strength of law enforcement, if police behaviors are the major driving force for the negative estimates in Table 2, one would expect a strong racial difference in the response of drug possession arrests. However, for both marijuana arrests and cocaine and heroin arrests, the estimates do not exhibit significant racial differences, and they are quantitatively similar to the results in Table 2 (but noisier). The estimates suggest an increase of about 10-15 percent in marijuana arrests and a decrease of roughly $0-15$ percent in cocaine and heroin arrests for both adult blacks and whites.

Even though the main components of medical marijuana laws are very similar from state to state, as briefly discussed in Section 2, they differ somewhat regarding the supply side. Since marijuana remains a Schedule I drug, none of these laws openly allowed dispensaries until New Mexico passed a law in 2007 that included a provision to license production and distribution at the state level. (The first state-licensed marijuana provider in New Mexico was not approved until March 2009.) The only exceptions are California and Colorado; their laws explicitly recognize the existence of dispensaries, even though they are silent as to their legality (Pacula et al. 2013). Earlier medical marijuana laws (prior to 2009) circumvent federal regulations by allowing home cultivation. By contrast, laws and amendments passed since 2009 specify regulations on dispensaries but generally do not allow home cultivation. In Table 4, I examine whether the effects of medical marijuana legalization on drug use are different when laws explicitly allow for dispensaries. Because of the ambiguity of the legal status of dispensaries in California and Colorado, the dummy variable Dispensary $\times$ Law does not include these two states. In columns 1 and 2 , the estimates for Dispensary $\times \operatorname{Law}_{s t}$ are consistent with the expectation that more complete legal protection would have a larger impact on marijuana use. However, because almost all of the laws allowing dispensaries were passed during the Obama administration, which has a relatively open attitude toward medical marijuana, the estimates may simply reflect a regime effect instead of a true policy difference. For cocaine and heroin arrests, in columns 5 and 6 , the estimates for Dispensary $\times \operatorname{Law}_{s t}$ are not significant and are very sensitive to time-trend specifications. In columns 3 and 7, I examine the two earliest states to implicitly allow dispensaries, California and Colorado, but they are not significantly different from other states except for one instance. When I estimate Dispensary $\times \mathrm{Law}_{s t}, \mathrm{CA} \times \mathrm{Law}_{s t}$, and $\mathrm{CO} \times \mathrm{Law}_{s t}$ together, the results are even noisier. Because most of the estimates for Dispensary $\times \operatorname{Law}_{s t}$ in Table 4 are quite noisy and not statistically different from the other estimates, they probably reflect only sampling errors rather than real differences in the policy effects. In fact, Anderson and Rees (2014) point out that the number of dispensaries is not

\footnotetext{
${ }^{15}$ Other racial categories in the Uniform Crime Reporting Program data are Asians and Native Alaskans or American Indians. The number of arrests for these races is very small.
} 


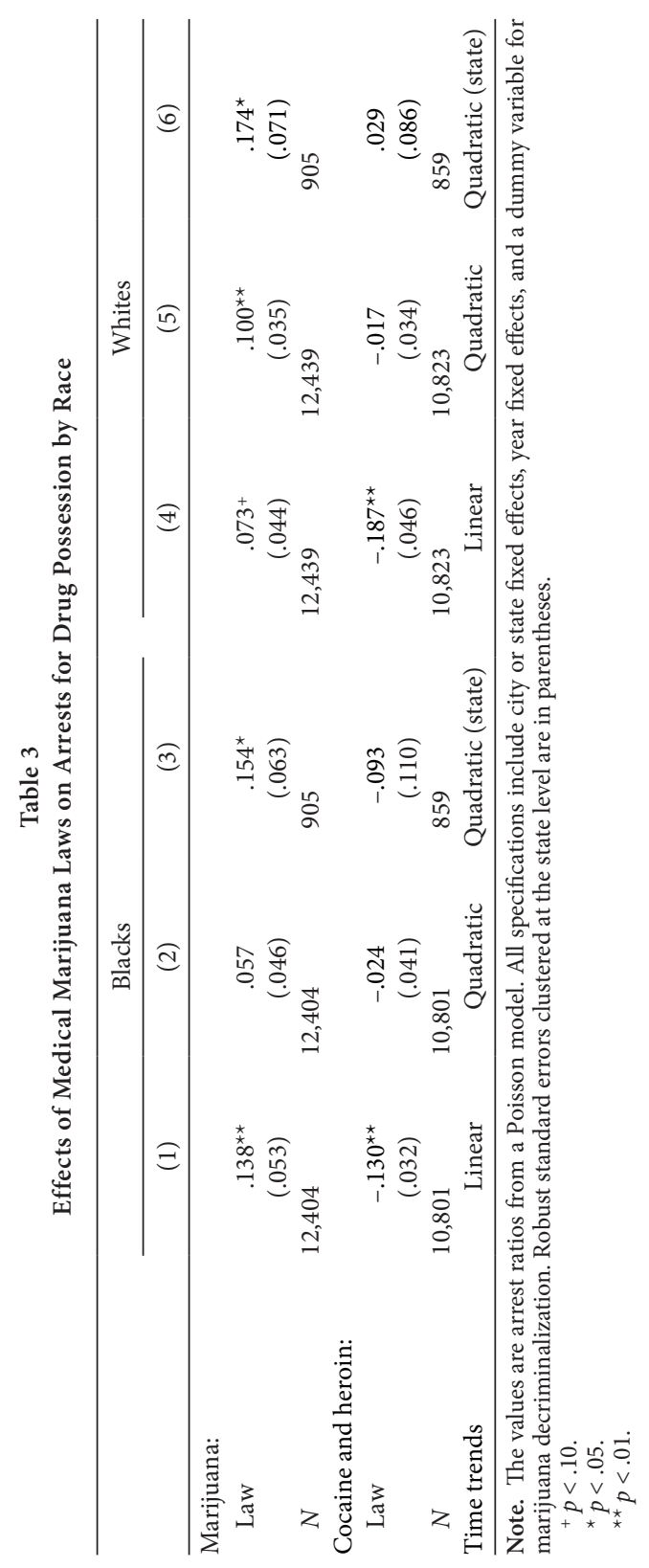




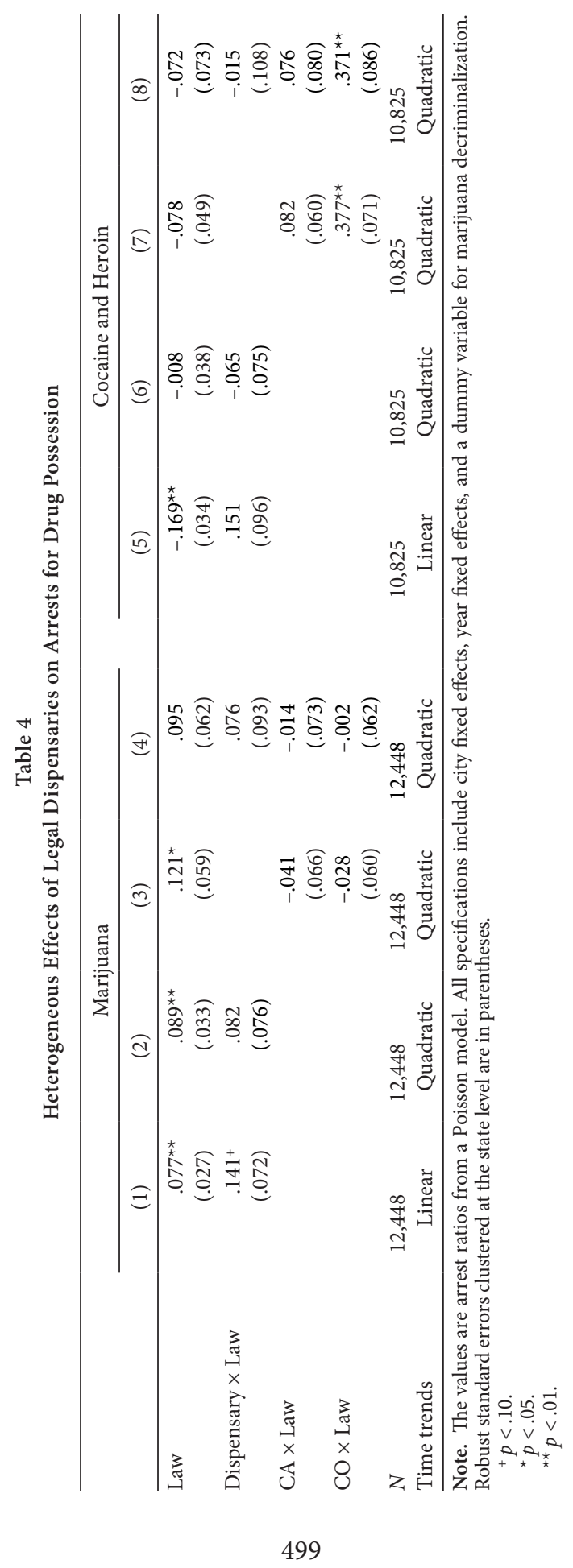


closely related to the question of whether state medical marijuana laws directly authorize dispensaries. For example, dispensaries did not become common in Colorado until 2009, and the first New Jersey dispensary did not open until 2012. Therefore, at least currently, the real difference in these laws may be small. But it is possible that some of the details in legislation will play a more important role in the future.

Figures 3-6 present evidence of the effects that medical marijuana laws have on marijuana and cocaine and heroin arrests. Figures 3 and 5 are based on the city-level samples. Since states with large populations like California are overrepresented in the city-level samples, Figures 4 and 6 are based on state-level averages. These graphs show the averages of marijuana or cocaine and heroin arrest ratios before and after medical marijuana laws became effective, with 0 on the $X$-axis denoting the first year of the law being effective. To create a synthetic control group, I first compute the average arrest ratios in non-medical-marijuana states for each year and then take a weighted average of these yearly averages, in which the weights are determined by the relative composition of each year in the treatment group (medical marijuana states). For example, for year 0 in the citylevel samples, around 57 percent of observations in the treatment group are from California, which passed its law in 1996, so the weight on the average of 1996 in the control group is .57. In other words, in year 0,57 percent of the observations in the control group are from 1996. Similarly, for year 0 from the state-level averages, only one of 13 observations in the treatment group is from California, and the weight on the average of 1996 in the control group is $1 / 13$. Figures 3 and 4 show that marijuana arrests are relatively flat in medical marijuana states compared with other states prior to medical marijuana legalization (year -4 to year -1$)$. On the other hand, the immediate increases in marijuana arrests from year -1 to year 1 (the first full year with effective medical marijuana laws) are much greater in the treatment group than in the control group, especially from the state-level averages in Figure 4. By contrast, in Figure 5, there is no significant change in cocaine and heroin arrests. For the state-level averages in Figure 6 , consistent with the negative estimates in Table 2, cocaine and heroin arrests in the treatment group appear to decrease after medical marijuana legalization.

One important topic in the literature is the potential intertemporal relationship between marijuana and other drugs, as in the popular gateway hypothesis. For example, there might exist lagged positive effects on cocaine and heroin use if marijuana is a gateway drug and people need some time to progress from marijuana to cocaine or heroin. To further investigate the dynamic responses of cocaine and heroin arrests to the adoption of medical marijuana laws, in Table 5 I replace $\mathrm{Law}_{s t}$ with a set of dummy variables that indicate each 2 -year interval after medical marijuana laws were enacted and a dummy for the 11th year and above. In columns 1 and 2, the estimates indicate that these laws have negative effects on cocaine and heroin arrests that are decreasing over time. To check whether cocaine and heroin arrests had been decreasing prior to medical marijuana legalization, I include an additional dummy that indicates the 2 -year interval be- 


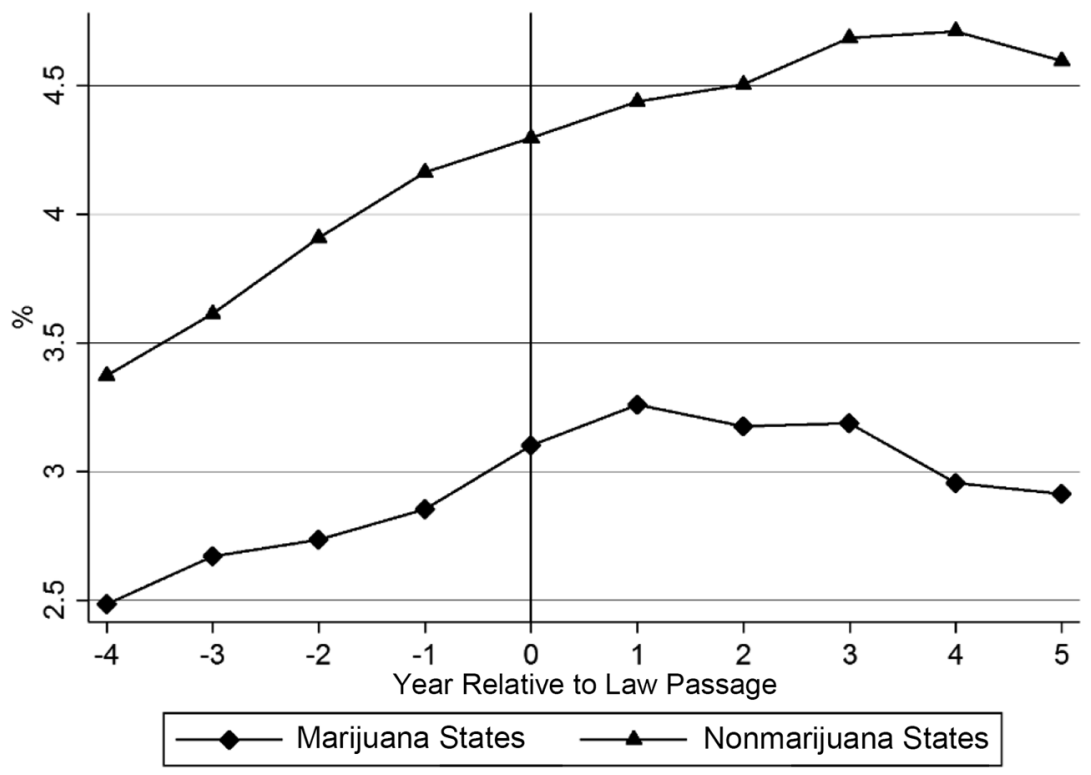

Figure 3. City-level marijuana arrest ratios before and after the passage of laws

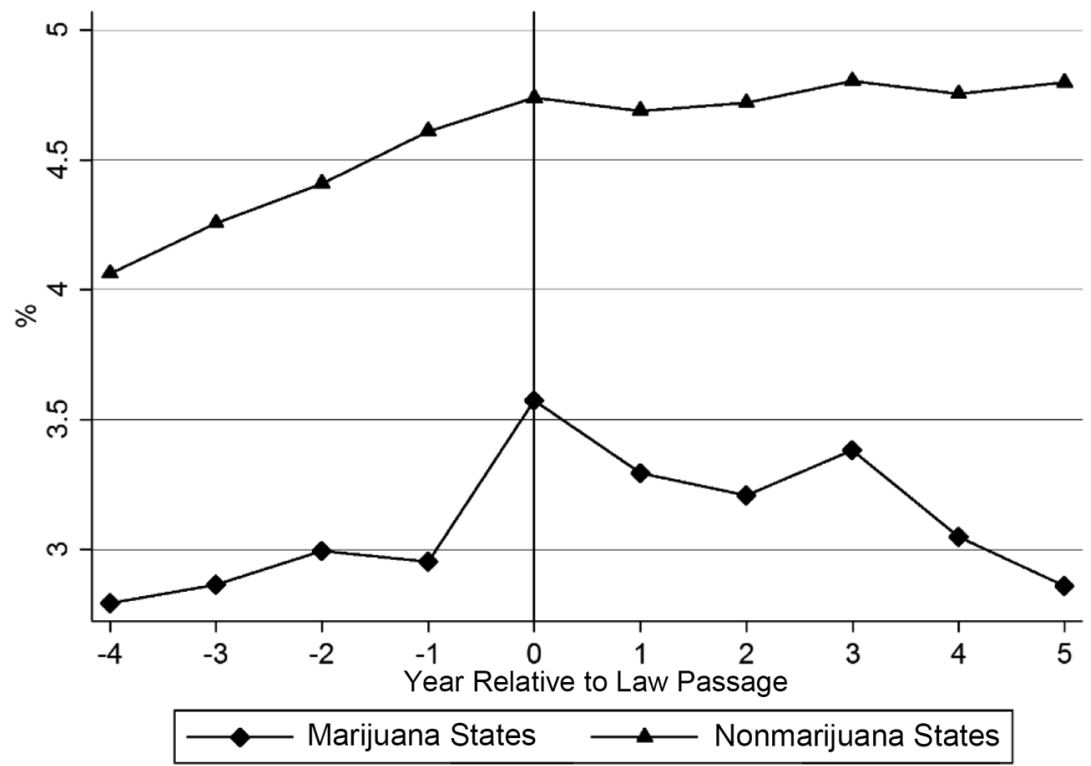

Figure 4. State-level marijuana arrest ratios before and after the passage of laws 


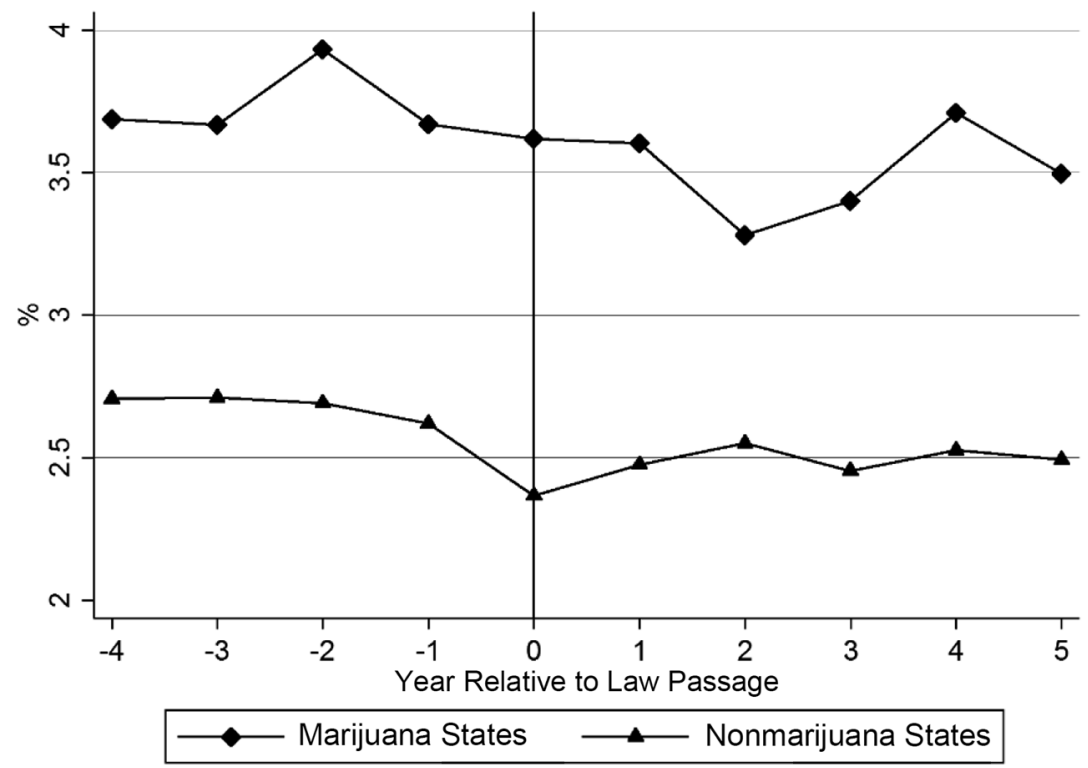

Figure 5. City-level cocaine and heroin arrest ratios before and after the passage of laws

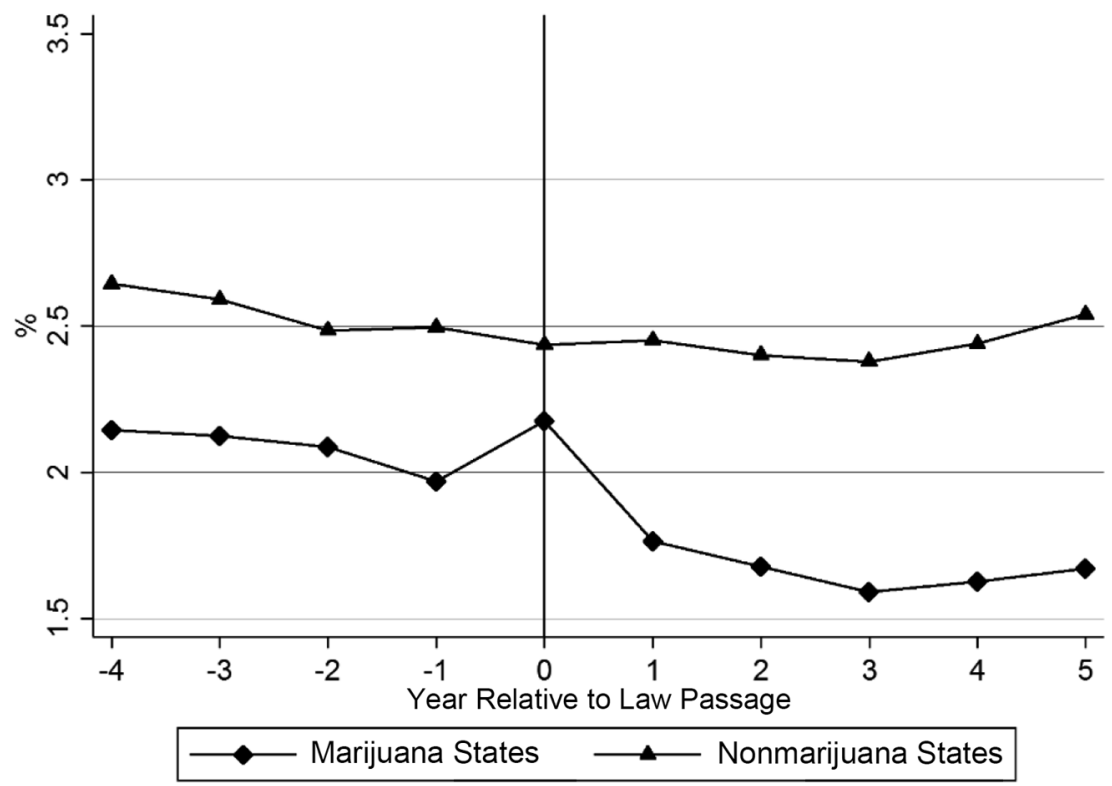

Figure 6. State-level cocaine and heroin arrest ratios before and after the passage of laws 
Table 5

Dynamic Responses of Arrests for Possession of Cocaine and Heroin to Medical Marijuana Laws

\begin{tabular}{lcccccc}
\hline & $(1)$ & $(2)$ & $(3)$ & $(4)$ & $(5)$ & $(6)$ \\
\hline Years -1 to -2 & & & .029 & $.068^{* *}$ & & -.026 \\
& & & $(.020)$ & $(.014)$ & & $(.047)$ \\
Year of law passage & -.128 & -.026 & -.077 & $.162^{+}$ & .039 & .007 \\
& $(.110)$ & $(.066)$ & $(.127)$ & $(.093)$ & $(.097)$ & $(.128)$ \\
Years 1-2 & $-.129^{*}$ & $-.077^{*}$ & $-.109^{*}$ & -.006 & -.065 & -.089 \\
& $(.052)$ & $(.038)$ & $(.060)$ & $(.034)$ & $(.074)$ & $(.090)$ \\
Years 3-4 & $-.174^{* *}$ & $-.109^{*}$ & $-.150^{* *}$ & -.023 & -.109 & -.138 \\
& $(.047)$ & $(.046)$ & $(.057)$ & $(.046)$ & $(.078)$ & $(.097)$ \\
Years 5-6 & $-.238^{\star *}$ & $-.200^{* *}$ & $-.209^{*}$ & -.104 & $-.234^{*}$ & $-.267^{*}$ \\
& $(.074)$ & $(.065)$ & $(.084)$ & $(.065)$ & $(.095)$ & $(.111)$ \\
Years 7-8 & $-.267^{* *}$ & $-.283^{* *}$ & $-.235^{*}$ & $-.181^{* *}$ & -.184 & $-.221^{+}$ \\
Years 9-10 & $(.096)$ & $(.059)$ & $(.110)$ & $(.058)$ & $(.126)$ & $(.118)$ \\
& $-.353^{* *}$ & $-.452^{* *}$ & $-.315^{*}$ & $-.346^{* *}$ & $-.375^{* *}$ & $-.415^{* *}$ \\
Years 11+ & $(.114)$ & $(.059)$ & $(.131)$ & $(.056)$ & $(.145)$ & $(.131)$ \\
& -.216 & $-.484^{* *}$ & -.170 & $-.377^{* *}$ & $-.360^{+}$ & $-.402^{*}$ \\
$N$ & $(.147)$ & $(.062)$ & $(.168)$ & $(.058)$ & $(.207)$ & $(.194)$ \\
Time trends & Linear & Quadratic & Linear & Quadratic & Quadratic & Quadratic \\
& & & & & $($ state $)$ & $($ state) \\
\hline
\end{tabular}

Note. The values are from a Poisson model and include all 50 states. All specifications include city or state fixed effects, year fixed effects, and a dummy variable for marijuana decriminalization. Robust standard errors clustered at the state level are in parentheses.

${ }^{+} p<.10$.
${ }^{*} p<.05$.
${ }_{* \star} p<.01$.

fore the laws were passed. In column 3, the estimate for Years -1 to -2 ) is small and insignificant; in column 4 , the estimate is positive. So policy endogeneity is not a particular concern in the current context. In columns 5 and 6, I estimate the dynamics using state-level averages, and they are quantitatively similar to the estimates based on the city-level sample. So the results are not driven by one or two large states. Note that the decreasing estimates in Table 5 are consistent with the state-level averages in Figure 6. Clearly, Table 5 indicates that there is no evidence supporting an intertemporal complementary effect or a gateway effect, that is, that marijuana use increases future hard-drug use. ${ }^{16}$

According to the UCR data, although marijuana arrests have increased since the passage of medical marijuana laws, there is no evidence that cocaine and heroin arrests have also increased. The results do not support the notion that mari-

\footnotetext{
${ }^{16}$ In a strict sense, the gateway hypothesis suggests that the initiation of soft drugs will progress to future use of hard drugs. It is clear that my reduced-form models cannot directly identify a gateway effect because of the lack of individual data. However, there is some evidence from Wen, Hockenberry, and Cummings (2014) that medical marijuana laws increase marijuana initiation rates (see also Table B2 in the online appendix). Because the gateway hypothesis predicts that these laws will have a positive effect on future hard-drug use, the contrary findings in Table 5 strongly reject the gateway hypothesis.
} 
juana is a complement to cocaine or heroin. One obvious limitation in these results is that they could be biased by unobserved changes in police actions. The direction of bias probably works against the above estimated effects, however. Many federal officials have expressed concern that local jurisdictions will opt out of marijuana enforcement (Eddy 2010). For example, in a letter responding to a report from the General Accounting Office (GAO 2002), the Department of Justice strongly complained that the report failed to consider the deteriorating relations between federal and local law enforcement (GAO 2002, app. 5). The report quotes some local law enforcement officials who when interviewed said that they would rather spend limited legal resources on pursuing hard drugs like crack cocaine instead of marijuana. At least on average, law enforcement related to marijuana is unlikely to increase while law enforcement related to cocaine or heroin is unlikely to decrease. Nevertheless, it is still a reasonable concern that changes in police behavior are driving the results above. For instance, police might shift enforcement from drug offenses toward other nondrug crimes in response to the passage of medical marijuana laws.

Another disadvantage of the UCR arrest data is that they do not separate cocaine and heroin. Cocaine is a stimulant, and its neurological effects are fundamentally different from those of depressants like heroin. Although marijuana is hard to classify, many of its neurological effects are more similar to those of depressants (Abood and Martin 1992; Domino 1971). For instance, both marijuana and heroin can relieve pain. Stimulants and depressants are often complements; for example, heroin can reduce the depression that ensues after the high from cocaine wears off, and it can also help with sleeping. Anecdotal evidence suggests that cocaine dealers are often also heroin dealers. If there really is a substitution with marijuana, as some of the negative estimates indicate, it is more likely between heroin and marijuana rather than between cocaine and marijuana. In Section 5, to further evaluate the impacts of medical marijuana laws separately on cocaine and heroin, I employ data on substance abuse treatment referrals from rehabilitation facilities.

\section{Results from the Treatment Episode Data Set}

\subsection{Treatment Episode Data Set}

The treatment admission data are from TEDS for 1992-2011 (SAMHSA 19922011). Similar to the UCR data, each admission does not uniquely identify an individual. For each admission, the data report up to three of the patient's substance abuse problems, demographics such as gender and age, and the sources of referral. About 40 percent of treatment referrals are from the criminal justice system, 30 percent are from individuals or the patients themselves, and 20 percent are from health care providers and substance abuse care providers. ${ }^{17}$

The TEDS admission data are from all substance abuse treatment facilities that

\footnotetext{
${ }^{17}$ The remaining 10 percent are referred by community or religious organizations and self-help groups such as Alcoholics Anonymous.
} 
receive public funding in each state. Some states collect data on all patients in publicly funded facilities, while others collect data only on publicly funded patients. The total number of admissions greatly fluctuates in some state-years, possibly because of changes in available funding or reporting practices. For example, the total number of treatments reported dropped to about half of previous levels in Washington after 1999. To account for the fluctuations in total admissions and capacity constraints of rehabilitation facilities, as commonly reported by SAMHSA, I create ratios of cocaine- or heroin-related treatments to all substance abuse treatments for each state as measures. Because each admission lists at most three drugs, I define marijuana-, cocaine-, and heroin-related treatment admissions as such if the drugs are identified as the primary, secondary, or tertiary abuse problem and marijuana-, cocaine-, and heroin-related primary treatment admissions as such only if the relevant drug is recorded as the primary abuse substance. Note that marijuana-related treatment ratios are more consistent with how drug use rates are defined in survey data. As juvenile hard-drugrelated treatments are rare, and to be consistent with the UCR arrests, I use only adult (ages 18 and above) treatment admissions. On the other hand, the potential gender differences in arrest risks are not a particular concern, I use both male and female admissions, to retain more observations. (The results from considering only male admissions are nearly identical.) The sample includes all medical marijuana states that passed laws before 2012. ${ }^{18}$ The summary statistics for marijuana-, cocaine-, and heroin-related treatment and primary treatment admission ratios are in Table $\mathrm{C} 2$ in the online appendix.

\subsection{Results}

To evaluate the effects of medical marijuana laws on substance abuse treatment admissions, I estimate the following model:

$$
\begin{aligned}
Y_{s t}= & f\left(\beta \text { Law }_{s t}+\right.\text { Year Fixed Effects } \\
t & + \text { State Fixed Effects } \\
& \left.+ \text { State Time Trends } \text { Tim }_{s t}+\text { Control Variables }_{s t}+\varepsilon_{s t}\right),
\end{aligned}
$$

where $Y_{s t}$ is the marijuana-, cocaine-, or heroin-related treatment or primary treatment ratio in state $s$ and year $t$. As in the previous analysis, I estimate equation (4) as a Poisson model or a log-linear model, and I cluster the standard errors at the state level. I focus on the specifications with specific time trends and with marijuana decriminalization as a single control variable to retain a larger sample size. ${ }^{19}$

Table 6 presents the estimated effects on substance abuse treatment ratios. Consistent with marijuana arrests in the UCR data, the estimated effects of medical marijuana laws are positive and suggest a 5.9 percent increase in marijuana-

\footnotetext{
${ }^{18}$ Arizona does not report data for 1992-97. Alaska does not report data for 2004-7. The District of Columbia does not report data for 1992, 1993, 2004-7, and 2009-10.

${ }^{19}$ In non-criminal-justice referrals, most of the estimates of decriminalization are small and insignificant.
} 


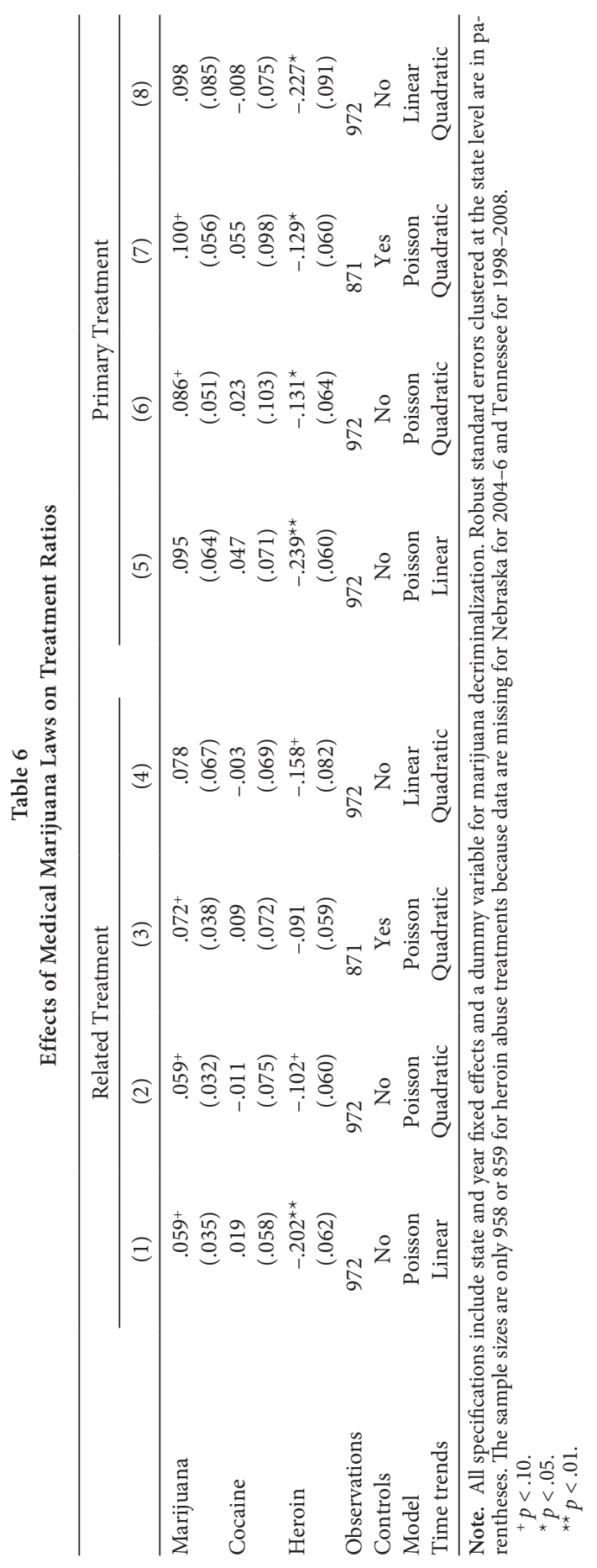


related treatments and an 8.6-9.5 percent increase in marijuana-related primary treatments after the passage of medical marijuana laws. However, the estimates on marijuana-related primary treatments are noisier. Although marijuana is the most popular illicit drug, and it accounts for one-third of total treatments, it is not highly addictive and accounts for only about 10 percent of primary treatments. For cocaine-related treatments, all of the estimates are small and never significant, and therefore they suggest no effects of medical marijuana laws on cocaine-related treatments. In contrast, the estimates on heroin-related treatments are negative and quite large in absolute terms. After the passage of medical marijuana laws, on average, heroin-related treatments decreased by 10.2-20.2 percent, and heroin-related primary treatments decreased by 13.1-23.9 percent. As a robustness check, I include the same set of state-level controls as in the UCR analysis. (The sample sizes are smaller because of missing data in these controls.) These results are similar to those in columns 1 and 2. In columns 4 and 8, I estimate equation (4) as a log-linear model, and the results remain quantitatively similar but with much larger estimated standard errors, especially for marijuana-related treatments. So the Poisson model appears to fit the data better. About 40 percent of the patients are criminal justice referrals. Although these criminal-justice-referred treatments are not directly linked to drug arrests, it is a legitimate concern that the results from the treatment data might be biased by potential changes in law enforcement, as in the arrest data. In Table D1 in the online appendix, I estimate the effects of medical marijuana laws on treatments due to non-criminal-justice referrals. The estimates for marijuana and heroin are greater in absolute terms and more significant, and the estimates for cocaine remain small and insignificant. ${ }^{20}$

As in the previous analysis from the UCR arrests, the results in Table 6 do not support a complementarity between marijuana and cocaine or heroin. In fact, there appears to be a decline in heroin usage and no change in cocaine usage. Figures 7-9, constructed in the same way as Figures 3-6, show the changes in marijuana-related treatment ratios, cocaine-related treatment ratios, and heroin-related treatment ratios before and after the passage of medical marijuana laws. The data in Figure 7 are quite noisy, but they exhibit a more rapid increase in treatment ratios in medical marijuana states. In Figure 8, for both states with and without medical marijuana laws, cocaine-related treatment ratios have a similar pattern of decreasing over time, which suggests that the legalization of medical marijuana has no effect on cocaine-related treatments. In Figure 9, the heroinrelated treatment ratios in medical marijuana states are roughly flat until a signif-

\footnotetext{
${ }^{20} \mathrm{I}$ also estimate separately the effects of laws that allow for dispensaries in Table D2 in the online appendix, and I do not find much evidence that allowing dispensaries implies different effects of these laws. Another concern is that the negative relationship between marijuana and heroin could be spurious and arises mechanically from the measure of treatment ratio. In Table D3 in the online appendix, the estimates based on treatment rates per 100,000 state residents are quantitatively similar and continue to suggest an increase in marijuana-related treatments and a decrease in heroinrelated treatments, even though they are significant only for heroin-related treatments. (The estimates for cocaine are sensitive to time-trend specifications and are never significant.)
} 


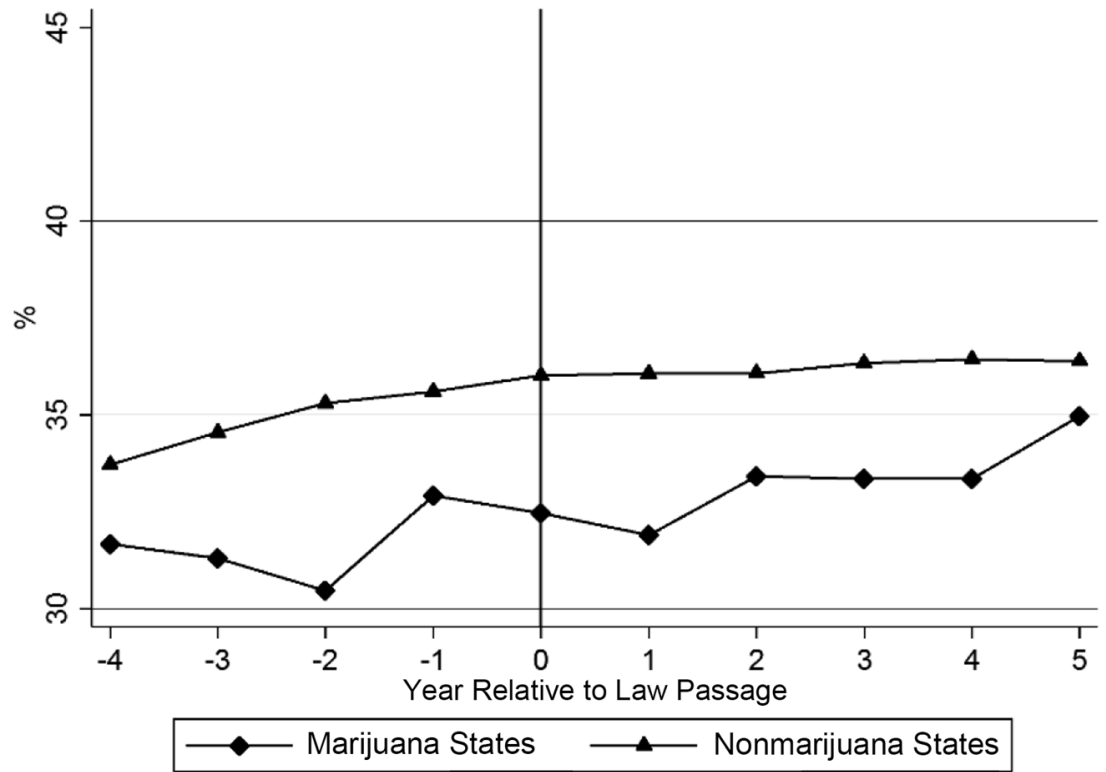

Figure 7. Marijuana-related treatment ratios before and after the passage of laws

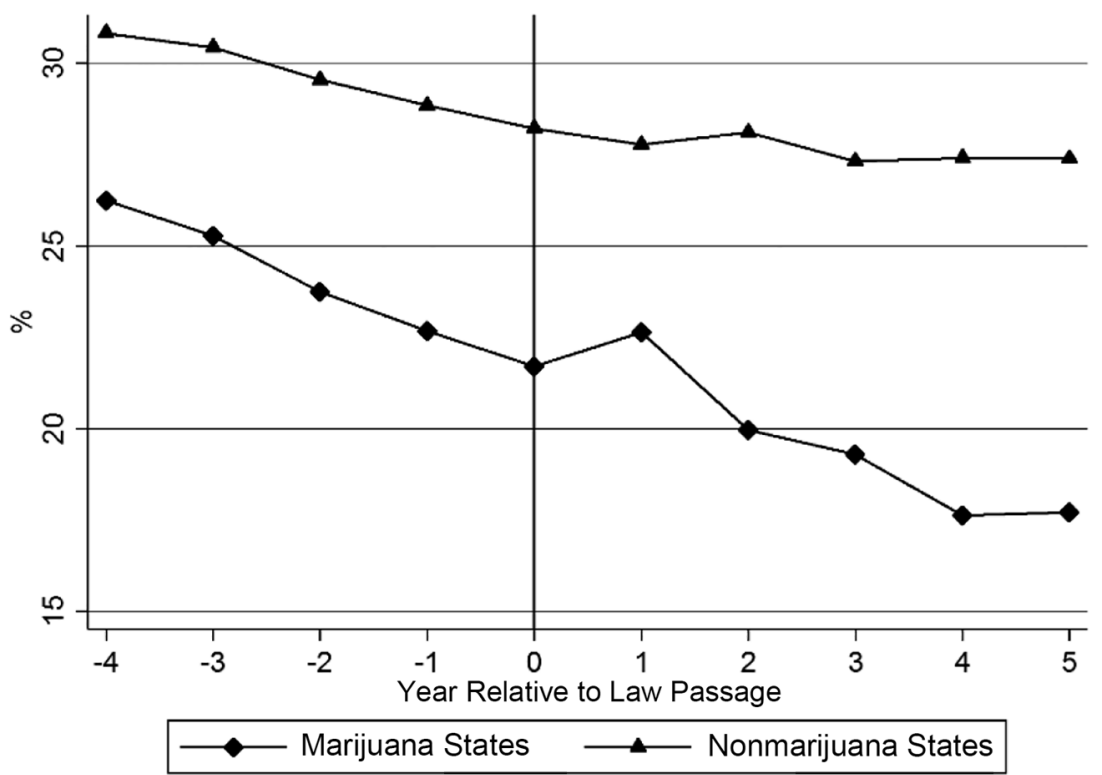

Figure 8. Cocaine-related treatment ratios before and after the passage of laws 


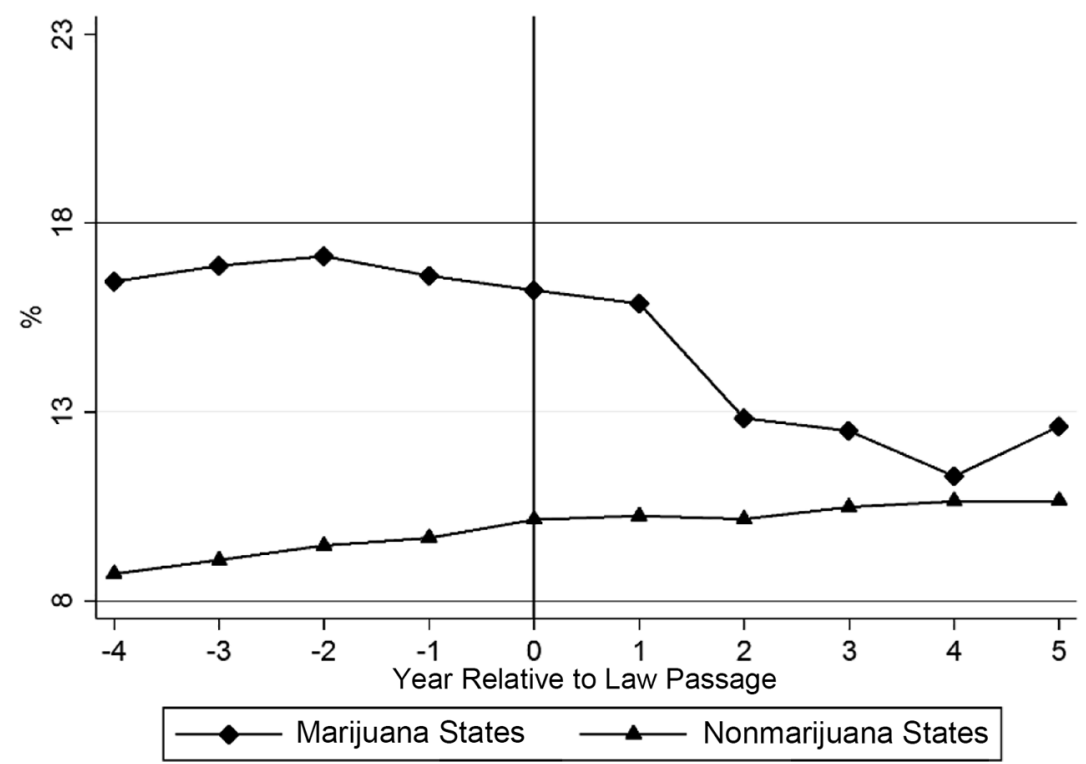

Figure 9. Heroin-related treatment ratios before and after the passage of laws

icant decrease after the passage of laws. By contrast, the heroin-related treatment ratios in states without laws slowly increase.

Multidrug abuse is common among cocaine- and heroin-related patients in treatment. In the sample, 30 percent of cocaine-related primary treatment patients reported marijuana abuse, and 40 percent of heroin-related primary treatment patients reported cocaine abuse. Moreover, the relationship is not symmetric: only 17 percent of marijuana-related primary treatment patients report cocaine abuse, and 5 percent of cocaine-related primary treatment patients report heroin abuse. The fact that patients who use harder drugs are more likely to use softer drugs (but not vice versa) is a major basis for the well-known gateway hypothesis. Although my estimates indicate that, on average, marijuana could be a substitute for heroin but has no direct relationship with cocaine, the substitution and complementarity between drugs may vary by different types of drug users, as some experimental studies suggest (Petry and Bickel 1998; Petry 2001; Jofre-Bonet and Petry 2008; Chalmers, Bradford, and Jones 2010). To investigate potential heterogeneous legalization effects, I focus on the two most common combinations in the TEDS data: cocaine-related primary treatments with marijuana-related treatments, which is the subset of cocaine-related primary treatments in which marijuana is either a secondary or tertiary abuse problem, and heroin-related primary treatments with cocaine-related treatments, which are defined in the same way. I also utilize the information on the routes of drug use to create speedball treatment ratios, a subset of heroin-related primary treat- 
Table 7

Effects of Medical Marijuana Laws on Multidrug Treatment Ratios, by Model

\begin{tabular}{|c|c|c|c|c|}
\hline & \multicolumn{2}{|c|}{ Poisson } & \multicolumn{2}{|c|}{ Log Linear } \\
\hline & (1) & (2) & (3) & (4) \\
\hline Cocaine with marijuana & $\begin{array}{c}.109 \\
(.089)\end{array}$ & $\begin{array}{c}.086 \\
(.109)\end{array}$ & $\begin{array}{c}.064 \\
(.093)\end{array}$ & $\begin{array}{c}.108 \\
(.106)\end{array}$ \\
\hline Heroin with cocaine & $\begin{array}{r}-.127^{\star} \\
(.057)\end{array}$ & $\begin{array}{l}-.182^{*} \\
(.079)\end{array}$ & $\begin{array}{r}-.250^{+} \\
(.125)\end{array}$ & $\begin{array}{r}-.188^{+} \\
(.109)\end{array}$ \\
\hline Speedball & $\begin{array}{l}-.080 \\
(.096)\end{array}$ & $\begin{array}{r}-.205^{\star} \\
(.092)\end{array}$ & $\begin{array}{r}-.257^{+} \\
(.144)\end{array}$ & $\begin{array}{r}-.229^{+} \\
(.132)\end{array}$ \\
\hline Time trends & Linear & Quadratic & Linear & Quadratic \\
\hline
\end{tabular}

Note. All specifications include state fixed effects, year fixed effects, and a dummy variable for marijuana decriminalization. Robust standard errors clustered at the state level are in parentheses.

$+p<.10$.

${ }^{*} p<.05$.

ments with cocaine treatments in which heroin injection is the primary problem and cocaine injection is the secondary or tertiary problem. ${ }^{21}$ Table 7 presents the estimated effects on treatment ratios of these drug combinations. All of the estimates for cocaine-related primary treatments with marijuana-related treatments are positive. Although the estimated standard errors are large, most of the magnitudes of the estimates are comparable to those for marijuana-related treatments in Table 6. The point estimates indicate roughly a 10 percent increase in treatments in which cocaine is the primary abuse problem and marijuana is the secondary abuse problem. Therefore, it is possible that a complementary effect of marijuana on cocaine, or even a gateway effect, may indeed exist for a subset of cocaine users. ${ }^{22}$ For patients in heroin-related primary treatments who also report cocaine abuse, including speedball patients, the estimated effects of the laws are negative and often significant, with a similar magnitude of decrease of around 10-20 percent as in Table 6. Therefore, the decline in the number of patients undergoing heroin-related treatment is similar regardless of whether they also use cocaine. ${ }^{23}$

${ }^{21}$ The summary statistics of these treatment ratios are presented in Table C3 in the online appendix. The sample sizes are a little smaller because of missing data in nonprimary drugs or routes of use.

${ }^{22}$ There is other evidence suggesting a potential complementary between marijuana and cocaine. From the public-use NSDUH data, the estimates for marijuana decriminalization in California and Massachusetts are positive for both marijuana and cocaine use (not reported). On the other hand, the estimates for marijuana-related treatments are nearly the same if I exclude admissions that report any cocaine use (not reported), so the increase in marijuana-related treatments is not a byproduct of an increase in (a subset of) cocaine-related treatments.

${ }^{23}$ The negative estimates for speedball-related treatments can partially address the concern that rehabilitation facilities might give priority to marijuana addicts because of these laws and therefore indirectly reduce the admissions of heroin patients because of capacity constraints. Since speedball abuse is probably the hardest form of abuse to treat, its admissions are less likely to be affected by these unobservable factors. 


\section{Discussion and Conclusion}

In this paper, using data on drug possession arrests and treatment admissions, I estimate reduced-form models for the effects of medical marijuana laws on these proxies for marijuana, cocaine, and heroin usage. My results indicate a 10-15 percent increase in marijuana use, likely on both the intensive and extensive margins, after the passage of medical marijuana laws. Although it is a widely accepted belief that marijuana is a complement to cocaine and heroin, at least for the subpopulation studied here, I do not find strong evidence supporting such a relationship between marijuana and cocaine or heroin. The possession arrests for cocaine and heroin combined do not significantly change or even appear to decrease after medical marijuana legalization. From the treatment data, I find a 10-20 percent decrease in heroin-related treatment admissions but no significant change in cocaine-related treatment admissions. Although these findings are fairly unexpected, they are consistent with findings from Wen, Hockenberry, and Cummings (2014) that medical marijuana laws do not increase cocaine and heroin use. The results from this study are also consistent with some qualitative studies that report medical marijuana patients substituting marijuana for alcohol and illegal drugs (Reiman 2009, 2007; Harris et al. 2000). In fact, some anecdotal evidence suggests that marijuana can ease the craving for heroin.

One obvious limitation of this study is that it relies largely on indirect measures of drug use. The estimates for drug arrests and treatments might be biased if police or treatment facilities respond endogenously to medical marijuana laws. In addition, medical marijuana laws may lower people's perception of the risks associated with marijuana, and potential patients may be less likely to seek treatment. It might be the case that individuals' perceptions become more favorable toward cocaine and heroin as well because of medical marijuana laws, and that might account for the negative estimates reported in this study. Another related limitation is that arrests and treatment admissions are not able to identify the extensive and intensive margins separately. Although this limitation does not change the qualitative interpretation, it makes quantitative interpretation much more difficult. Even if there is indeed a substitution effect between marijuana and heroin, it is unclear at which margins people substitute their consumption. In fact, I intentionally avoid using terms such as "elasticity of substitution" to interpret these reduced-form results, as these estimates theoretically capture effects at both margins. As heroin is one of the most addictive drugs, a reasonable guess would be that any potential substitution effect is largely at the intensive margin. Future studies will contribute to this literature by separately identifying changes in the extensive and intensive margins.

Results in this study suggest that, on average, marijuana is probably a substitute for heroin, but heroin use is not strongly correlated with cocaine use. However, the relationships between substances may be heterogeneous and depend on different types of users. For instance, this paper suggests that there is a potential positive effect on patients who use cocaine with marijuana but a negative ef- 
fect on patients who use cocaine with heroin. To evaluate the impacts of medical marijuana laws, future research should consider these potential heterogeneous effects carefully. Because of constraints such as sample sizes in currently available data sets, qualitative studies with detailed and extensive descriptions of drug-use behaviors may be as important as quantitative studies.

\section{References}

Abood, Mary E., and Billy R. Martin. 1992. Neurobiology of Marijuana Abuse. Trends in Pharmacological Sciences 13:201-6.

Agrawal, Arpana, Michael C. Neale, Carol A. Prescott, and Kenneth S. Kendler. 2004. Cannabis and Other Illicit Drugs: Comorbid Use and Abuse/Dependence in Males and Females. Behavior Genetics 34:217-28.

Akiyama, Yoshio, and Sharon K. Propheter. 2005. Methods of Data Quality Control: For Uniform Crime Reporting Programs. April. Washington, DC: Federal Bureau of Investigation.

Altieri, Erik. 2012. The Republican Candidates on Marijuana. Alternet.org, January 9. http:// www.alternet.org/story/153699/the_republican_candidates_on_marijuana.

Anderson, D. Mark, Benjamin Hansen, and Daniel I. Rees. 2012. Medical Marijuana Laws and Teen Marijuana Use. Discussion Paper No. 6592. Institute for the Study of Labor, Bonn.

2013. Medical Marijuana Laws, Traffic Fatalities, and Alcohol Consumption. Journal of Law and Economics 56:333-69.

- Forthcoming. Medical Marijuana Laws and Teen Marijuana Use. American Law and Economics Review. doi:10.1093/aler/ahv002.

Anderson, D. Mark, and Daniel I. Rees. 2014. The Role of Dispensaries: The Devil Is in the Details. Journal of Policy Analysis and Management 33:235-40.

Anderson, Erik. 2012. "Mother Earth" Medical Marijuana Clinic Prepares to Close. KPBS Public Broadcasting. September 3.http://www.kpbs.org/news/2012/sep/03/mother-earth -prepares-close-medical-marijuana-clin/.

Arkes, Jeremy, Rosalie Liccardo Pacula, Susan M. Paddock, Jonathan P. Caulkins, and Peter Reuter. 2008. Why the DEA STRIDE Data Are Still Useful for Understanding Drug Markets. Working Paper No. 14224. National Bureau of Economic Research, Cambridge, MA.

Becker, Gary S., and Kevin M. Murphy. 1988. A Theory of Rational Addiction. Journal of Political Economy 96:675-700.

Beckett, Katherine, Kris Nyrop, and Lori Pfingst. 2006. Race, Drugs, and Policing: Understanding Disparities in Drug Delivery Arrests. Criminology 44:105-37.

Beckett, Katherine, Kris Nyrop, Lori Pfingst, and Melissa Bowen. 2005. Drug Use, Drug Possession Arrests, and the Question of Race: Lessons from Seattle. Social Problems 52:419-41.

Bound, John, and Gary Solon. 1999. Double Trouble: On the Value of Twins-Based Estimation of the Return to Schooling. Economics of Education Review 18:169-82.

Bretteville-Jensen, Anne L., Hans O. Melberg, and Andrew M. Jones. 2008. Sequential Patterns of Drug Use Initiation: Can We Believe in the Gateway Theory? BE Journal of Economic Analysis and Policy 8(2) (Contributions), art. 1, pp. 1-31.

Caplan, Gerald. 2012. Medical Marijuana: A Study of Unintended Consequences. McGeorge 
Law Review 43:127-46.

Carpenter, Christopher. 2007. Heavy Alcohol Use and Crime: Evidence from Underage Drunk-Driving Laws. Journal of Law and Economics 50:539-57.

Cerdá, Magdalena, Melanie Wall, Katherine M. Keyes, Sandro Galea, and Deborah Hasin. 2012. Medical Marijuana Laws in 50 States: Investigating the Relationship between State Legalization of Medical Marijuana and Marijuana Use, Abuse, and Dependence. Drug and Alcohol Dependence 120:22-27.

Chalmers, Jenny, Deborah Bradford, and Craig Jones. 2010. The Effect of Methamphetamine and Heroin Price on Polydrug Use: A Behavioural Economics Analysis in Sydney, Australia. International Journal of Drug Policy 21:381-89.

Choo, Esther K., Madeline Benz, Nikolas Zaller, Otis Warren, Kristin L. Rising, and K. John McConnell. 2014. The Impact of State Medical Marijuana Legislation on Adolescent Marijuana Use. Journal of Adolescent Health 55:160-66.

Chu, Yu-Wei Luke. 2014. The Effects of Medical Marijuana Laws on Illegal Marijuana Use. Journal of Health Economics 38:43-61.

Cohen, Peter J. 2010. Medical Marijuana 2010: It's Time to Fix the Regulatory Vacuum. Journal of Law, Medicine, and Ethics 38:654-66.

Coté, John, Erin Allday, Wyatt Buchanan, and Marisa Lagos. 2008. Feds Say S.F. Has More Pot Clubs Than Starbucks, but It Might Not Add Up. San Francisco Chronicle, November 18. http://www.sfgate.com/health/article/Feds-say-S-F-has-more-pot-clubs-than-Starbucks -3260991.php.

Dannerbeck, Anne, Gardenia Harris, Paul Sundet, and Kathy Lloyd. 2006. Understanding and Responding to Racial Differences in Drug Court Outcomes. Journal of Ethnicity in Substance Abuse 5:1-22.

DEA (Drug Enforcement Administration). 1991. DEA History Book, 1985-1990. Washington, DC: DEA. http://www.dea.gov/about/history/1985-1990.pdf.

. 2013. The DEA Position on Marijuana. Washington, DC: US Department of Justice, Drug Enforcement Administration. April. http://www.dea.gov/docs/marijuana _position_2011.pdf.

DeSimone, Jeffrey. 1998. Is Marijuana a Gateway Drug? Eastern Economic Journal 24:14964.

Deza, Monica. 2015. Is There a Stepping Stone Effect in Drug Use? Separating State Dependence from Unobserved Heterogeneity within and between Illicit Drugs. Journal of Econometrics 184:193-207.

Dickinson, Tim. 2012. Obama's War on Pot. Rolling Stone, February 16. http://www.rolling stone.com/politics/news/obamas-war-on-pot-20120216.

Domino, Edward F. 1971. Neuropsychopharmacologic Studies of Marijuana: Some Synthetic and Natural THC Derivatives in Animals and Man. Annals of the New York Academy of Sciences 191:166-91.

Donohue, John J., III, and Steven D. Levitt. 2001. The Impact of Race on Policing and Arrests. Journal of Law and Economics 44:367-94.

Eddy, Mark. 2010. Medical Marijuana: Review and Analysis of Federal and State Policies. Congressional Research Service Report No. RL33211. Washington, DC: Congressional Research Service.

Ellgren, Maria, Sabrina M. Spano, and Yasmin L. Hurd. 2007. Adolescent Cannabis Exposure Alters Opiate Intake and Opioid Limbic Neuronal Populations in Adult Rats. Neuropsychopharmacology 32:607-15.

FBI (Federal Bureau of Investigation). 1992-2011. Uniform Crime Reporting Program 
Data: Arrests by Age, Sex, and Race, Summarized Yearly (computer file). Ann Arbor, MI: Inter-university Consortium for Political and Social Research.

Fellner, Jamie. 2009. Race, Drugs, and Law Enforcement in the United States. Stanford Law and Policy Review 20:257-91.

Fergusson, David M., Joseph M. Boden, and L. John Horwood. 2006a. Cannabis Use and Other Illicit Drug Use: Testing the Cannabis Gateway Hypothesis. Addiction 101:55669.

. 2006b. Testing the Cannabis Gateway Hypothesis: Replies to Hall, Kandel et al., and MacCoun (2006). Addiction 101:474-76.

Fryer, Roland G., Jr., Paul S. Heaton, Steven D. Levitt, and Kevin M. Murphy. 2013. Measuring Crack Cocaine and Its Impact. Economic Inquiry 51:1651-81.

GAO (General Accounting Office). 2002. Marijuana: Early Experiences with Four States' Laws That Allow Use for Medical Purposes. Report No. GAO-03-189. November. Washington, DC: GAO.

Golub, Andrew, Hilary James Liberty, and Bruce D. Johnson. 2005. Inaccuracies in Self-Reports and Urinalysis Tests: Impacts on Monitoring Marijuana Use Trends among Arrestees. Journal of Drug Issues 35:941-65.

Gorman, Dennis M., and Charles Huber, Jr. 2007. Do Medical Cannabis Laws Encourage Cannabis Use? International Journal of Drug Policy 18:160-67.

Gross, Samuel R., and Katherine Y. Barnes. 2002. Road Work: Racial Profiling and Drug Interdiction on the Highway. Michigan Law Review 101:651-754.

Grossman, Michael, and Frank J. Chaloupka. 1998. The Demand for Cocaine by Young Adults: A Rational Addiction Approach. Journal of Health Economics 17:427-74.

Harper, Sam, Erin C. Strumpf, and Jay S. Kaufman. 2012. Do Medical Marijuana Laws Increase Marijuana Use? Replication Study and Extension. Annals of Epidemiology 22:207-12.

Harris, Debra, Reese T. Jones, Robin Shank, Rajneesh Nath, Emilio Fernandez, Kenneth Goldstein, and John Mendelson. 2000. Self-Reported Marijuana Effects and Characteristics of 100 San Francisco Medical Marijuana Club Members. Journal of Addictive Diseases 19:89-103.

Harrison, Lana, and Arthur Hughes, eds. 1997. The Validity of Self-Reported Drug Use: Improving the Accuracy of Survey Estimates. Research Monograph No. 167. Rockville, MD: National Institute on Drug Abuse, Division of Epidemiology and Prevention Research.

Hernández-Murillo, Rubén, and John Knowles. 2004. Racial Profiling or Racist Policing? Bounds Tests in Aggregate Data. International Economic Review 45:959-89.

Horowitz, Joel L. 2001. Should the DEA's STRIDE Data Be Used for Economic Analyses of Markets for Illegal Drugs? Journal of the American Statistical Association 96:1254-62.

Jofre-Bonet, Mireia, and Nancy M. Petry. 2008. Trading Apples for Oranges? Results of an Experiment on the Effects of Heroin and Cocaine Price Changes on Addicts' Polydrug Use. Journal of Economic Behavior and Organization 66:281-311.

Kandel, Denise. 1975. Stages in Adolescent Involvement in Drug Use. Science 190:912-14. 2003. Does Marijuana Use Cause the Use of Other Drugs? JAMA: The Journal of the American Medical Association 289:482-83.

Kandel, Denise B., Kazuo Yamaguchi, and Laura Cousino Klein. 2006. Testing the Gateway Hypothesis. Addiction 101:470-72.

Khatapoush, Shereen, and Denise Hallfors. 2004. "Sending the Wrong Message": Did Medical Marijuana Legalization in California Change Attitudes about and Use of Marijuana? Journal of Drug Issues 34:751-70. 
Leger, Donna Leinwand. 2012. Survey: 1 in 15 High School Seniors Smoking Pot. USA Today, Dec. 20. http://www.usatoday.com/story/news/nation/2012/12/19/national-drug -survey-youth-marijuana/1779563/.

Levitt, Steven D. 1998. Juvenile Crime and Punishment. Journal of Political Economy 106:1156-85.

Lynch, James P., and John P. Jarvis. 2008. Missing Data and Imputation in the Uniform Crime Reports and the Effects on National Estimates. Journal of Contemporary Criminal Justice 24:69-85.

Lynne-Landsman, Sarah D., Melvin D. Livingston, and Alexander C. Wagenaar. 2013. Effects of State Medical Marijuana Laws on Adolescent Marijuana Use. American Journal of Public Health 103:1500-1506.

Lynskey, Michael T., Andrew C. Heath, Kathleen K. Bucholz, Wendy S. Slutske, Pamela A. F. Madden, Elliot C. Nelson, Dixie J. Statham, and Nicholas G. Martin. 2003. Escalation of Drug Use in Early-Onset Cannabis Users vs. Co-twin Controls. JAMA: The Journal of the American Medical Association 289:427-33.

Lynskey, Michael T., Jacqueline M. Vink, and Dorret I. Boomsma. 2006. Early Onset Cannabis Use and Progression to Other Drug Use in a Sample of Dutch Twins. Behavior Genetics 36:195-200.

MacCoun, Robert. 1998. In What Sense (If Any) Is Marijuana a Gateway Drug? Drug Policy Analysis Bulletin 4:5-8.

- 2006. Competing Accounts of the Gateway Effect: The Field Thins, but Still No Clear Winner. Addiction 101:473-74.

Melberg, Hans Olav, Andrew M. Jones, and Anne Line Bretteville-Jensen. 2010. Is Cannabis a Gateway to Hard Drugs? Empirical Economics 38:583-603.

Mikos, Robert A. 2011. A Critical Appraisal of the Department of Justice's New Approach to Medical Marijuana. Stanford Law and Policy Review 22:633-69.

Miller, Riane N., and Joseph B. Kuhns. 2012. Exploring the Impact of Medical Marijuana Laws on the Validiy of Self-Reported Marijuana Use among Juvenile Arrestees over Time. Criminal Justice Policy Review 23:40-66. doi:10.1177/0887403410392026.

Moffatt, Steve, Wai-Yin Wan, and Don Weatherburn. 2012. Are Drug Arrests a Valid Measure of Drug Use? A Time Series Analysis. Policing: An International Journal of Police Strategies and Management 35:458-67.

National Public Radio. 2009. In California, Marijuana Dispensaries Outnumber Starbucks. October 15. http://www.npr.org/templates/story/story.php?storyId=113822156.

O'Connor, Anahad. 2011. Marijuana Use Growing among Teenagers. New York Times, December 14. http://well.blogs.nytimes.com/2011/12/14/marijuana-growing-in-popularity -among-teenagers/.

Office of National Drug Control Policy. 2012. National Drug Control Strategy Data Supplement 2012. Washington, DC: Office of National Drug Control. http://www.white house.gov/sites/default/files/ondcp/2012_ndcs.pdf Policy.

O'Keefe, Karen, and Mitch Earleywine. 2011. Marijuana Use by Young People: The Impact of State Medical Marijuana Laws. Washington, DC: Marijuana Policy Project.

Pacula, Rosalie L., Anne E. Boustead, and Priscillia Hunt. 2014. Words Can Be Deceiving: A Review of Variation among Legally Effective Medical Marijuana Laws in the United States. Journal of Drug Policy Analysis 7:1-19.

Pacula, Rosalie Liccardo, David Powell, Paul Heaton, and Eric L. Sevigny. 2013. Assessing the Effects of Medical Marijuana Laws on Marijuana and Alcohol Use: The Devil Is in the Details. Working Paper No. 19302. National Bureau of Economic Research, Cam- 
bridge, MA.

Parker, Karen F., and Scott R. Maggard. 2005. Structural Theories and Race-Specific Drug Arrests: What Structural Factors Account for the Rise in Race-Specific Drug Arrests over Time? Crime and Delinquency 51:521-47.

Petry, Nancy M. 2001. A Behavioral Economic Analysis of Polydrug Abuse in Alcoholics: Asymmetrical Substitution of Alcohol and Cocaine. Drug and Alcohol Dependence 62:31-39.

Petry, Nancy M., and Warren K. Bickel. 1998. Polydrug Abuse in Heroin Addicts: A Behavioral Economic Analysis. Addiction 93:321-35.

ProCon.org. 2013. 23 Legal Medical Marijuana States and DC: Laws, Fees, and Possession Limits. http://medicalmarijuana.procon.org/view.resource.php?resourceID=000881.

Pudney, Stephen. 2003. The Road to Ruin? Sequences of Initiation to Drugs and Crime in Britain. Economic Journal 113:C182-C198.

Ramchand, Rajeev, Rosalie Liccardo Pacula, and Martin Y. Iguchi. 2006. Racial Differences in Marijuana-Users' Risk of Arrest in the United States. Drug and Alcohol Dependence 84:264-72.

Reiman, Amanda. 2007. Medical Cannabis Patients: Patient Profiles and Health Care Utilization Patterns. Journal of Evidence-Based Complementary and Alternative Medicine $12: 31-50$

2009. Cannabis as a Substitute for Alcohol and Other Drugs. Harm Reduction Journal 6 (1), art. 35, pp. 1-5.

Rosenfeld, Richard, and Scott H. Decker. 1999. Are Arrest Statistics a Valid Measure of Illicit Drug Use? The Relationship between Criminal Justice and Public Health Indicators of Cocaine, Heroin, and Marijuana Use. Justice Quarterly 16:685-99.

Saffer, Henry, and Frank Chaloupka. 1999. The Demand for Illicit Drugs. Economic Inquiry 37:401-11.

Salomonsen-Sautel, Stacy, Joseph T. Sakai, Christian Thurstone, Robin Corley, and Christian Hopfer. 2012. Medical Marijuana Use among Adolescents in Substance Abuse Treatment. Journal of the American Academy of Child and Adolescent Psychiatry 51:694-702.

SAMHSA (Substance Abuse and Mental Health Services Administration). 1992-2011. Treatment Episode Data Set-Admissions (TEDS-A) (computer file). Ann Arbor, MI: Inter-university Consortium for Political and Social Research.

Sekhon, Vijay. 2009. Highly Uncertain Times: An Analysis of the Executive Branch's Decision to Not Investigate or Prosecute Individuals in Compliance with State Medical Marijuana Laws. Hastings Constitutional Law Quarterly 37:553-63.

Solinas, M., L. V. Panlilio, and S. R. Goldberg. 2004. Exposure to $\Delta$-9-Tetrahydrocannabinol (THC) Increases Subsequent Heroin Taking but Not Heroin's Reinforcing Efficacy: A Self-Administration Study in Rats. Neuropsychopharmacology 29:1301-11.

Terry-McElrath, Yvonne M., Jamie F. Chriqui, Hannalori Bates, and Duane C. McBride. 2014. Do State Policies Matter in Prosecutor-Reported Juvenile Marijuana Case Disposition? Criminology and Penology 60:402-26.

Thurstone, Christian, Shane A. Lieberman, and Sarah J. Schmiege. 2011. Medical Marijuana Diversion and Associated Problems in Adolescent Substance Treatment. Drug and Alcohol Dependence 118:489-92.

van Ours, Jan C. 2003. Is Cannabis a Stepping-Stone for Cocaine? Journal of Health Economics 22:539-54.

Wall, Melanie M., Ernest Poh, Magdalena Cerdá, Katherine M. Keyes, Sandro Galea, and Deborah S. Hasin. 2011. Adolescent Marijuana Use from 2002 to 2008: Higher in States 
with Medical Marijuana Laws, Cause Still Unclear. Annals of Epidemiology 21:714-16. . 2012. Commentary on Harper S, Strumpf EC, Kaufman JS: Do Medical Marijuana Laws Increase Marijuana Use? Replication Study and Extension. Annals of Epidemiology 22:536-37.

Warner, Barbara D., and Brandi Wilson Coomer. 2003. Neighborhood Drug Arrest Rates: Are They a Meaningful Indicator of Drug Activity? A Research Note. Journal of Research in Crime and Delinquency 40:123-38.

Wen, Hefei, Jason M. Hockenberry, and Janet R. Cummings. 2015. The Effect of Medical Marijuana Laws on Adolescent and Adult Use of Marijuana, Alcohol, and Other Substances. Journal of Health Economics 42:64-80. doi:10.1016/j.jhealeco.2015.03.007.

Wright, Douglas. 2004. State Estimates of Substance Use from the 2002 National Survey on Drug Use and Health. Rockville, MD: Substance Abuse and Mental Health Services Administration, Office of Applied Studies.

Zaitchik, Alexander. 2008. All Indicators Point to a Softening of America's Harsh Marijuana Laws. Alternet.org, June 2. http://www.alternet.org/story/86982/all_indicators_ point_to_a_softening_of_america\%27s_harsh_marijuana_laws. 